\title{
Investigation of SVPWM Based Sliding Mode Control Application on Dual-Star Induction Motor and Dual Open-End Winding Induction Motor
}

\author{
Mourad Sellah, Abdellah Kouzou ${ }^{1 *}$, Mohamed Mounir Rezaoui ${ }^{1}$ \\ ${ }^{1}$ LAADI Laboratory, Faculty of Sciences and Technology, Ziane Achour University of Djelfa, P. O. B. 3117 , Moudjbara Street, 17000 Djelfa, \\ Algeria \\ * Corresponding author, e-mail: kouzouabdellah@ieee.org
}

Received: 22 January 2021, Accepted: 25 May 2021, Published online: 10 December 2021

\begin{abstract}
The present paper deals with a comparative study of the Sliding Mode Control (SMC) technique application on three-phase Dual Star Induction Motor (DSIM) topology and the Dual Open-End Winding Induction Motor (DOEWIM). Where, in these two topologies the Space Vector Pulse Width Modulation (SVPWM) has been used for the control of the two two-level inverters and the four twolevel inverters, which have been used to power the two motors under application respectively. The main objective of this study is to demonstrate the higher performances of the DOEWIM under the application of SMC combined with SVPWWM, which aims to overcome the main drawbacks faced when using the conventional topology DSIM in industrial applications. Especially in terms of decreasing the harmonics content in the stator current, reducing the overall ripples of the developed electromagnetic torque, the elimination of the common mode voltage and increasing the robustness against the load torque variation and speed reverse. The obtained simulation results show clearly the main advantages of using the topology of DOEWIM compared to the DSIM topology which present a very promising application especially in heavy industrial requiring high power motors.
\end{abstract}

Keywords

common mode voltage, dual open-end winding induction motor, dual star induction motor, sliding mode control, space vector pulse width modulation

\section{Introduction}

Recently, the multi-phase machines have attracted the attention of many researchers, manufacturers and industrial due to their main features in overcoming many problems faced with the conventional three-phase machines. Indeed, the multi-phase machines offer an interesting alternative to reducing constraints on switches and windings where the multiplication of the number of phases allows splitting the power and currents among more number of phases. In addition, these machines can reduce the amplitude and the ripples of the developed torque, moreover, grants increased reliability by enabling operations in the event of one phase fault or two no-consecutive faulty phases $[1,2]$. This feature allows them to have many properties such as low maintenance, robustness, scalability. Consequently, they gains more characteristics of flexibility and comfort, which pave the path for them to become widely used in high power applications, such as railway traction, naval propulsion, compressors and cement mills [2, 3].
One of the most common examples of multiphase machines is the DSIM, which is considered a six-phase machine. The use of this machine which was practically only on three-phase machines, has two coils with a certain offset between them at the level of the stator. This configuration allows to benefit from the advantages of the classic induction machine that was extensively used in most industrial applications [4]. Furthermore, the DSIM offers in addition to the advantages of induction machines, those of multiphase machines, such as: power segmentation, minimization of torque ripples and rotor losses, reduction of harmonic currents, high reliability against power supply faults and it can be used in high-power applications [3-6]. In order to improve the service quality of the DSIM and ensure their control in different industrial applications with higher reliability, this kind of machine is proposed to be used with the topology of open stator windings, so the machine is no longer a DSIM but it is a dual Stator 
open-end winding IM (DOEWIM) [7-10]. Under this new configuration, it is necessary to control the machine using four three-phase voltage systems with specific shift phases between the four power voltage systems to ensure the elimination of the common-mode voltage which is considered one of the inherent characteristics when high frequency DC/AC converters are used to ensure their control [11, 12] such as the bearing currents and shaft voltages, which leads to rapid failures of machine bearings and shafts. On the other side due to the use of two inverters from each side of the both windings, the voltage applied to each phase will be seen as multi-level voltage, hence the quality of applied voltage will be improved $[7,8,13-15]$.

However, to improve the output voltage, various modulation strategies have been developed. Among these strategies, the SVPWM, which represents the most adopted modulation method in asynchronous machines control due to its ability in eliminating the undesired harmonics components in the voltage applied at the motor terminals, which guarantees the reduction of torque ripples, moreover, this control technique allows maintaining the switching frequency non-variable [16-18].

For many years, several control approaches have been applied for the control of the DSIM, in particular the Field Oriented Control (FOC) which has shown good performance in transient and permanent regimes [5, 19, 20]. But these performances may be insufficient, because this conventional control law is not robust especially when the requirements on the accuracy and other dynamic characteristics of the systems are strict due to its sensitivity to parametric variations [19]. In this paper, it is proposed the application of the sliding mode control which is part of the family of Variable Structure Controllers (VSC). Indeed, the originality of the present work reside on the application of the SMC with DSIM under stator open-end winding which has not been presented before in the literature as a main research work. On the other side, this paper focusses also in minimizing the influence of FOC problems thank to main advantages of SMC such as the high precision, the fast dynamic response, the stability, the simplicity of design and implementation and robustness to the variation of internal or external parameters [21, 22].

This paper is divided to the introduction, four main sections (Sections 1 to 5) and a conclusion (Section 6), the Section 1 presents the modeling of the DSIM with highlighting the new configuration of this machine based on opening of the two ends of each stator windings to convert it to DOEWIM. The Section 2 presents the theoretical background of SWPWM and its application on the control of the inverters driving the proposed motor topology. Section 3 is reserved to the presentation of the SMC and its application in combination with the FOC and SVPWM on the DSIM and the proposed motor topology DOEWIM. Section 4 a comparative study based on simulation results, between these two motors is carried out taking into account a deep analysis of the performance of each motor under different practical situations. Finally, this paper ends with a conclusion.

\section{Description and modeling of DSIM and DOEWIM 2.1 DSIM modeling}

In the classical configuration, the DSIM stator winding is compound of two identical balanced three-phase windings, which are shifted by an electric angle of $(\pi / 6 \mathrm{rad})$ and they have the same number of poles. Whereas, the rotor structure remains similar to the three-phase machine induction machine which is considered in this study as a quarrel cage [23]. The equivalent windings circuits of the stator and rotor are shown in Fig. 1.

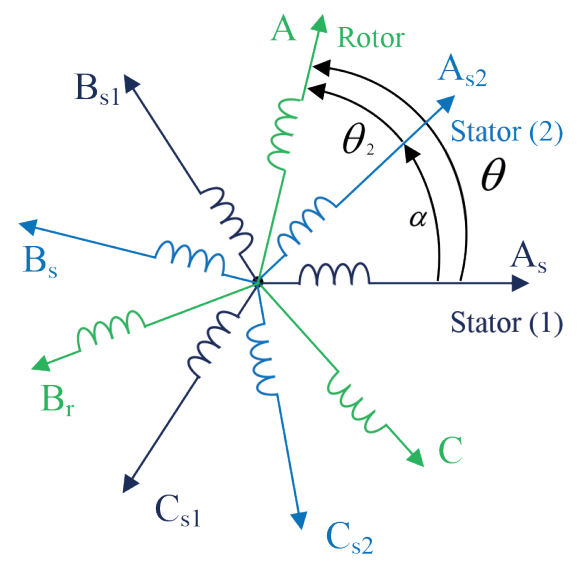

Fig. 1 The presentation of DSIM winding

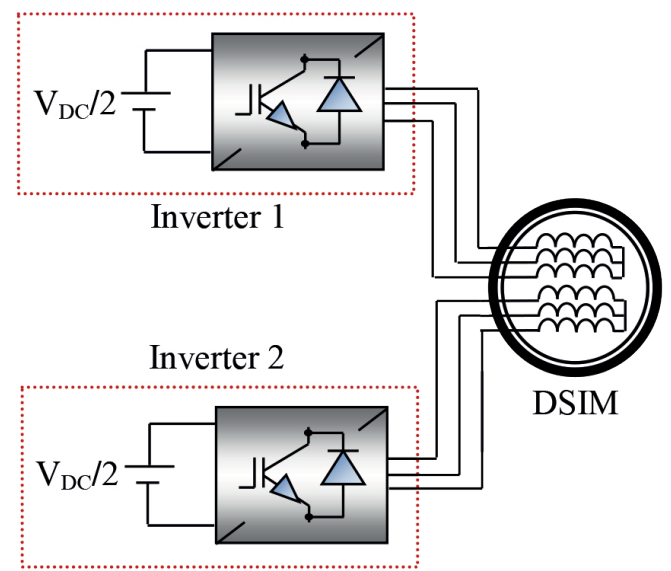

Fig. 2 The principle of DSIM fed by two inverters 
In this configuration of the DSIM the both windings are fed by two identical separated inverters, which are powered by a two similar separated DC sources in this study as shown in Fig. 2.

In this study, the reference frame fixed to the rotating field was chosen, for the purpose of having constant values in steady state. It is then easier to control the motor, so the Park model of the DSIM is given as follows:

1. The stator and rotor voltages:

$$
\left\{\begin{array}{l}
V_{s d 1}=R_{s 1} I_{s d 1}+\frac{d}{d t} \varphi_{s d 1}-\omega_{s} \varphi_{s q 1} \\
V_{s q 1}=R_{s 1} I_{s q 1}+\frac{d}{d t} \varphi_{s q 1}-\omega_{s} \varphi_{s d 1} \\
V_{s d 2}=R_{s 2} I_{s d 2}+\frac{d}{d t} \varphi_{s d 2}-\omega_{s} \varphi_{s q 2} \\
V_{s q 2}=R_{s 2} I_{s q 2}+\frac{d}{d t} \varphi_{s q 2}-\omega_{s} \varphi_{s d 2} \\
V_{r d}=R_{r} I_{r d}+\frac{d}{d t} \varphi_{r d}-\left(\omega_{s}-\omega_{r}\right) \varphi_{r q}=0 \\
V_{r q}=R_{r} I_{r q}+\frac{d}{d t} \varphi_{r q}-\left(\omega_{s}-\omega_{r}\right) \varphi_{r d}=0
\end{array}\right.
$$

with:

$R_{s 1}, R_{s 2}$ : Stator resistances of star 1 and 2, respectively. $R_{r}$ : Rotor resistance.

$V_{s d 1}, V_{s q 1}$ : First star voltages in the Park referential $(d, q)$.

$V_{s d 2}, V_{s q 2}$ : Second star voltages in the Park referential $(d, q)$.

$I_{s d 1}, I_{s q 1}$ : First star currents in the Park referential $(d, q)$.

$I_{s d 2}, I_{s q 2}$ : Second star currents in the Park referential $(d, q)$.

$\varphi_{s d 1}, \varphi_{s q 1}$ : First star fluxes in the Park referential $(d, q)$.

$\varphi_{s d 2}, \varphi_{s q 2}:$ Second star fluxes in the Park referential $(d, q)$.

2. The stator and rotor flux expressions are:

$$
\text { are }:\left\{\begin{array}{l}
\varphi_{s d 1}=L_{s 1} I_{s d 1}+L_{m}\left(I_{s d 1}+I_{s d 2}+I_{r d}\right) \\
\varphi_{s q 1}=L_{s 1} I_{s q 1}+L_{m}\left(I_{s q 1}+I_{s q 2}+I_{r q}\right) \\
\varphi_{s d 2}=L_{s 2} I_{s d 2}+L_{m}\left(I_{s d 1}+I_{s d 2}+I_{r d}\right) \\
\varphi_{s q 2}=L_{s 2} I_{s q 2}+L_{m}\left(I_{s q 1}+I_{s q 2}+I_{r q}\right) \\
\varphi_{r d}=L_{r} I_{r d}+L_{m}\left(I_{s d 1}+I_{s d 2}+I_{r d}\right) \\
\varphi_{r q}=L_{r} I_{r q}+L_{m}\left(I_{s q 1}+I_{s q 2}+I_{r q}\right)
\end{array}\right.
$$

with:

$L_{s 1}, L_{s 2}$ : Stator inductance of star 1 and 2, respectively.

$L_{r}:$ Rotor inductance.

$L_{m}$ : Mutual inductance.

$I_{r d}, I_{r q}$ : Rotor currents in the Park referential $(d, q)$.

$\varphi_{r d}, \varphi_{r q}$ : Rotor fluxes in the Park referential $(d, q)$.

3. The mechanical equation:

$$
\frac{J}{P} \frac{d \omega_{r}}{d t}=T_{e m}-T_{L}-\frac{K_{f}}{P} \omega_{r}
$$

where:

$T_{e m}$ : electromagnetic torque.

$T_{L}$ : Load torque.

$P$ : Number of pole pairs.

$J$ : Moment of inertia.

$K_{f}$ : Friction coefficient.

4. The electromagnetic torque:

$$
T_{e m}=P \frac{L_{m}}{L_{m}+L_{r}}\left\{\varphi_{r d}\left(I_{s q 1}+I_{s q 2}\right)-\varphi_{r q}\left(I_{s d 1}+I_{s d 2}\right)\right\} .
$$

\subsection{DOEWIM with four level configuration}

The DOEWIM is a machine that has twelve stator terminals, six for each stator winding, Hence, four groups of three terminals are obtained, which require four threephase inverters to ensure powering and controlling the studied machine. As shown in Fig. 3. Indeed, two twolevel three-phase inverters 1 and 3 are used for the first winding, while the two two-level three-phase inverter 3 and 4 are used for the second stator winding.

In this configuration to ensure the required input power for the four inverters two separated DC-sources are used for each winding, Hence the voltage which will be applied to the first winding and to the second winding will be seen as they are powered separately by two three-phase

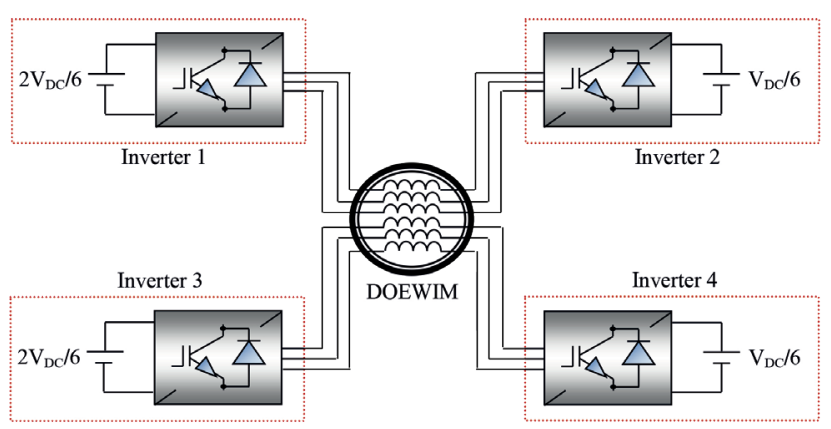

Fig. 3 The principle of DOEWIM fed by four inverters 
inverters having an output voltage with levels greater than two-levels. On the other side an interesting advantage appears that there is no coupling among the phase's windings in both stator windings and therefore the common voltage is vanished as shown in Fig. 3. In the present work, to achieve a four-level output voltage that will be applied to the both windings, asymmetrical DC-sources are chosen for powering the inverters. In this case the output voltage of DC-sources of inverter 1 and 2 are chosen equal to $(2 / 6) V_{D C}$ and $(1 / 6) V_{D C}$, respectively as proposed previously in $[24,25]$. In the same way, the inverters 3 and 4 are power by Dc sources of $(2 / 6) V_{D C}$ and $(1 / 6) V_{D C}$, respectively where the main constraints that the sum between two DC-sources voltages applied to each winding will be equal to $(2 / 6) V_{D C}$, here $V_{D C}$ a fixed values taken as a reference depending on the application and the used machine.

It is important to clarify that the absence of a common mode voltage in each three-phase stator winding allows eliminating the flow of current through the motor case, thus we the bearing lifespan will be increased remarkably [25]. The voltages $V_{a 1}, V_{b 1}, V_{c 1}, V_{a^{\prime} 1}, V_{b^{\prime} 1}, V_{c^{\prime} 1}$ are, respectively the output voltages at the terminals of the inverters 1 and 2, which are feeding the first ends of the both sides of the first stator winding, and are, respectively the output voltages at the terminals of the other inverters 3 and 4, which are feeding the second ends of the both side of the second stator winding. So, the voltage across each of three-phase of both stator winding can be obtained by the difference between the voltages applies at the terminals of each phase as follows:

- The first stator winding:

$$
\left\{\begin{array}{l}
V_{a a^{\prime} 1}=V_{a o 1}-V_{a^{\prime} o 1} \\
V_{b b^{\prime} 1}=V_{b o 1}-V_{b^{\prime} o 1} \\
V_{c c^{\prime} 1}=V_{c o 1}-V_{c^{\prime} o 1}
\end{array}\right.
$$

- The second stator winding:

$$
\left\{\begin{array}{l}
V_{a a^{\prime} 2}=V_{a o 2}-V_{a^{\prime} o 2} \\
V_{b b^{\prime} 2}=V_{b o 2}-V_{b^{\prime} o 2} \\
V_{c c^{\prime} 2}=V_{c o 2}-V_{c^{\prime} o 2}
\end{array} .\right.
$$

The resulting space vectors of the two voltages applied to the two-stator winding can be furthermore represented based in vector form as follows:

$$
\begin{aligned}
& V_{r e f 1}=V_{a a^{\prime} 1}+V_{b b^{\prime} 1} e^{j \frac{2 \pi}{3}}+V_{c c^{\prime} 1} e^{j \frac{4 \pi}{3}} \\
& V_{r e f 2}=V_{a a^{\prime} 2} e^{j \frac{\pi}{6}}+V_{b b^{\prime} 2} e^{j \frac{5 \pi}{6}}+V_{c c^{\prime} 2} e^{j \frac{9 \pi}{6}}
\end{aligned}
$$

\section{SVPWM technique}

The SVPWM control technique is widely for all the topologies of inverters in several applications, especially for electrical machines control due its main advantages compared to other control techniques such as low harmonics content in the output voltage, less loses in the semiconductor switches and high ratio of voltage conversion [26]. In this paper, the SVPWM is used to ensure the control of the four inverters where the main aim is that the voltages, which will be applied across the both stator windings with less harmonics.

\subsection{Two level DC-SVPWM algorithm}

The four used inverters will be controlled in the same way using the same technique. Indeed, the basic idea of the three-phase two-level inverter is well known, it is composed of three legs to ensure the three-phase output voltage. Two switches are placed in each leg, which are controlled in a complementary manner to avoid the short-circuit of the DC input power supply and the interruption of the current flow in the corresponding phase. All the six switches constituting the inverter can have eight possible combination switching states [23].

The main objective of SVPWM technique is the determination of the time portions (modulation time) that must be allocated to each voltage vector during the sampling period in order to reconstruct the reference output voltage vector $\boldsymbol{V}_{\text {sref }}$ from eight voltage vectors shown in Fig. 4 and which are corresponding to each possible switching state of the three-phase two level inverter. This reference voltage is representing the voltage which should be applied to one winding side of the DSIM presented in this paper.

A reference voltage vector $\boldsymbol{V}_{\text {sref }}$ is calculated globally and approximated over a modulation period $T_{e}$ by an average voltage vector $\boldsymbol{V}_{\text {smoy }}$, the latter is elaborated by the application of the adjacent voltage vectors and the null vectors $\boldsymbol{V}_{0}$ and $\boldsymbol{V}_{7}$. Each two adjacent vector represent a sector, in the present case there are six sectors. Fig. 4 shows the representation of the eight state voltage vectors of the threephase two-level inverters in the $\alpha, \beta$ frame,six non-zero vectors are the active vectors and two zero vectors.

Assuming that the reference vector is in sector 1 . The time of the application of the adjacent vectors is given as follows:

$$
\frac{1}{T_{S}} \int_{0}^{T_{S}} \bar{V}_{r e f} \mathrm{~d} t=\frac{1}{T_{S}}\left\{\int_{0}^{T_{1}} \bar{V}_{1} \mathrm{~d} t+\int_{T_{1}}^{T_{1}+T_{2}} \bar{V}_{2} \mathrm{~d} t+\int_{T_{1}+T_{2}}^{T_{S}} \bar{V}_{0} \mathrm{~d} t\right\},
$$




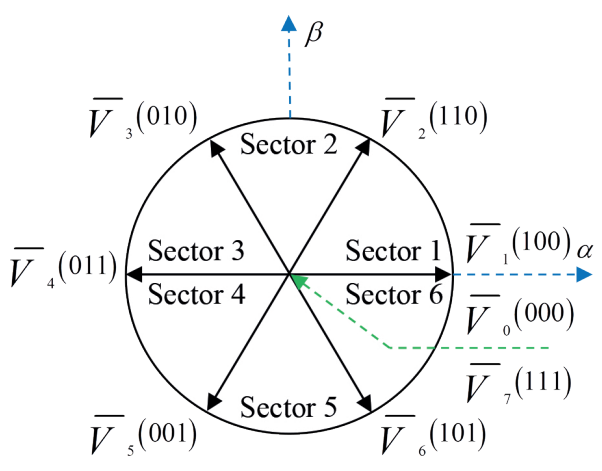

Fig. 4 The representation of space vectors corresponding to each switching states of an inverter

$T_{s} \bar{V}_{\text {ref }}=T_{1} \bar{V}_{1}+T_{2} \bar{V}_{2}$

$\bar{V}_{r e f}=\frac{T_{1}}{T_{s}} \bar{V}_{1}+\frac{T_{2}}{T_{s}} \bar{V}_{2}$,

where: $T_{s}=T_{1}+T_{2}+T_{0}$, and $T_{s}$ : is the inverter switching period.

\subsection{Proposed four level DC-SVPWM algorithm}

The SVPWM of the DOEWIM depends directly on the commutation states and their space vector locations resulting from the two-by-two combinations of the four inverters feeding the two-stator windings. It uses specific voltage vectors that do not produce zero-sequence voltages and therefore eliminates of unwanted zero-sequence currents [27].

Fig. 5 illustrates all the possible space vector locations from the inverters 1 and 2 that feed the first stator winding independently, the space vector locations from other inverters 3 and 4 that feed the second stator winding are identical to those provided by inverters 1 and 2 .

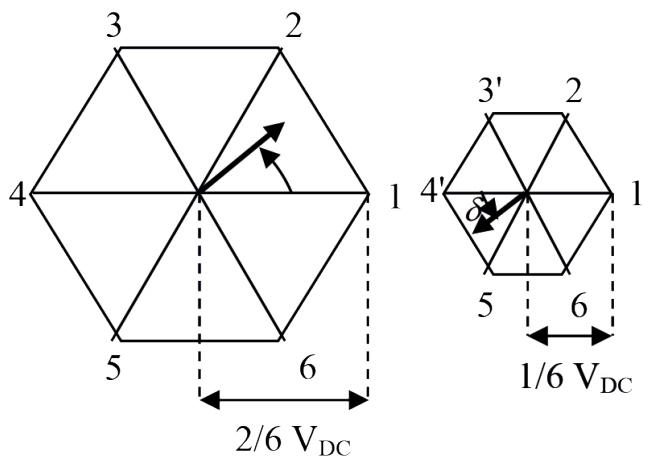

Fig. 5 The location of the space vectors for the two inverters feeding the first stator: inverter-1 (left) and inverter-2 (right)

As we mentioned before that each inverter has the ability to produce eight commutation states, so in this new configuration which is based on the combination of two inverters, it can ensure the generation of $64\left(8^{2}\right)$ commutation states corresponding to 37 different possible space vectors, these vectors divide the plane into 54 sectors of equilateral triangles, their vertices are presenting the ends or tips of the space vectors and their edges have a length of $V_{D C} / 6$ as shown in Fig. $6[24,25]$.

The vectors $\boldsymbol{O} \boldsymbol{T}$ and $\boldsymbol{O}^{\prime} \boldsymbol{T}^{\prime}$ with the magnitudes $\left(\left|V_{\text {ref }}\right|,\left|V_{\text {ref }}^{\prime}\right|\right)$ and the phases $(\delta, \delta-\pi / 6)$, respectively, represent the two reference voltage space vectors, which must be synthesized from the combination of the two inverters in both stator windings to ensure the four levels voltage to be applied across the different phase windings within the both stator windings of the DOEWIM. It is important to clarify that the two inverters which are connected to the same windings such as the first winding or second winding, have to generate an outputs voltage with a phase shift of $180^{\circ}(\pi \mathrm{rad})$ between the output voltages of the two, inverter of the same
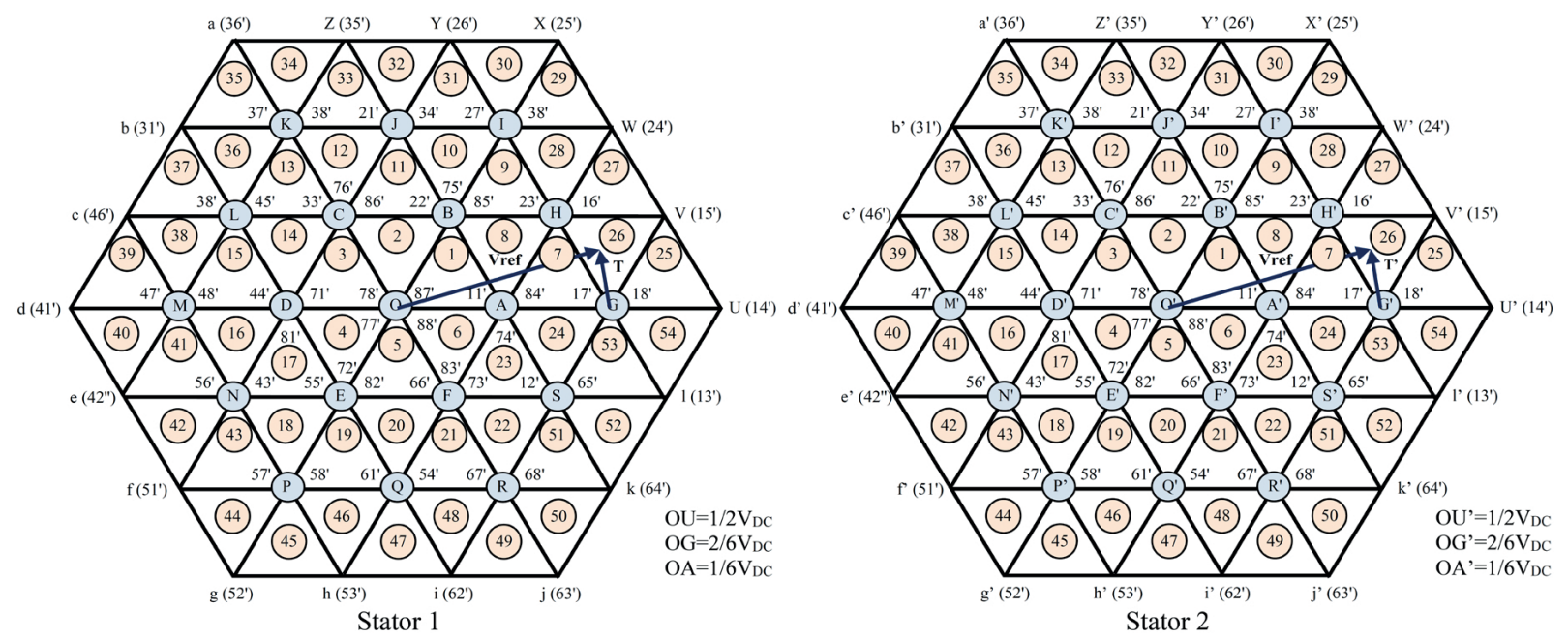

Fig. 6 The resultant space-vector combinations of the two dual-inverters scheme 
stator winding. So that each of the two space vectors $\boldsymbol{O T}$ and $\boldsymbol{O}^{\prime} \boldsymbol{T}^{\prime}$ is decomposed into two opposite components, the first one is decomposed to $O A\left(\left|2 V_{r e f}^{\prime} / 3\right|, \arg (\delta)\right)$ and $A T\left(\left|V_{r e f}^{\prime} / 3\right|, \arg (\delta-\pi)\right)$, while the second one is decomposed to $O^{\prime} A^{\prime}\left(\left|2 V_{\text {ref }}^{\prime} / 3\right|, \arg (\delta-\pi / 6)\right)$ and $A^{\prime} T^{\prime}\left(\left|V_{\text {ref }}^{\prime} / 3\right|, \arg (\delta-7 \pi / 6)\right)$ as shown in Fig. 6 , such that the vector $\boldsymbol{O A}$ and $\boldsymbol{A T}$ are synthesized by the two inverters of the first stator winding $O^{\prime} A^{\prime}$ and $A^{\prime} T^{\prime}$ are synthesized by the two inverters of the second stator winding [26].

As long as the four inverters, which are used for powering the DOEWIM are two-level inverters, each inverter is responsible of producing an output voltage with two values. On the other side, these inverters are operated with separated DC sources with voltages of $2 V_{D C} / 6$ for inverters 1 and 3, and of $V_{D C} / 6$ for inverters 2 and 4 . Consequently, the voltages of the outputs take the two values $V_{D C} / 6$ or $V_{D C} / 6$ for inverters 1 and 3 , and $V_{D C} / 12$ or $V_{D C} / 12$ for the inverters 2 and 4 . The resulting voltages applied across the both winding is presenting the difference of voltages between inverters 1 and 2 for the first stator winding, and of inverters 3 and 4 for the second stator winding as presented in Table $1[10,28]$.

\section{Sliding mode control design}

\subsection{Theory of sliding mode control}

The sliding mode control is a nonlinear control strategy which is based on forcing the system state trajectory to reach a predefined sliding surface and hence converging to a permanent mode along this sliding surface. Indeed, the design of the SMC takes into account two main problems such as the stability and the improved performance in a systematic way [23, 29]. This issue can be achieved within three ordered complementary steps which are defined as follows:

Table 1 Pole and phase voltages of the 4-level inverter

\begin{tabular}{lcc}
\hline $\begin{array}{l}\text { Pole-voltage of } \\
\text { inverter } 1\end{array}$ & $\begin{array}{r}\text { Pole-voltage of } \\
\text { inverter } 2\end{array}$ & $\begin{array}{c}\text { Stator 1 phase } \\
\text { voltage }\end{array}$ \\
\hline$-V_{D C} / 6$ & $V_{D C} / 12$ & $-V_{D C} / 4$ \\
$-V_{D C} / 6$ & $-V_{D C} / 12$ & $-V_{D C} / 12$ \\
$V_{D C} / 6$ & $V_{D C} / 12$ & $V_{D C} / 12$ \\
$V_{D C} / 6$ & $-V_{D C} / 12$ & $V_{D C} / 4$ \\
\hline Pole-voltage of & Pole-voltage of & Stator 2 phase \\
inverter 3 & inverter 4 & voltage \\
\hline$-V_{D C} / 6$ & $V_{D C} / 12$ & $-V_{D C} / 4$ \\
$-V_{D C} / 6$ & $-V_{D C} / 12$ & $-V_{D C} / 12$ \\
$V_{D C} / 6$ & $V_{D C} / 12$ & $V_{D C} / 12$ \\
$V_{D C} / 6$ & $-V_{D C} / 12$ & $V_{D C} / 4$ \\
\hline
\end{tabular}

- choice of the sliding surfaces;

- establishment of existence and convergence conditions;

- determination of the control law.

\subsubsection{Choice of the sliding surfaces}

A general time-varying surface function was proposed in [30] to ensure the convergence of the state variable $x$ to its reference value $x^{*}$. This function is expressed as follows:

$S(x, t)=\left(\frac{d}{d t}+\lambda\right)^{r-1} e(x)$,

with: $S(x, t)$ : Sliding surface of the variable $x$.

$\lambda$ is a strictly positive gain, $e(x)=x^{*}-x$ is the error on the state variable to be regulated, $r$ is the sliding mode degree which presents the smallest positive integer such that $\partial \dot{S}(t) / \partial t \neq 0$ ensures the controllability.

\subsubsection{Establishment of existence and convergence conditions}

The conditions of existence and convergence are the criteria which allow the different dynamics of the system to converge towards the sliding surface and to remain there independently of the disturbances [31]. Among these criteria, the Lyapunov approach which is used in this paper. Consequently, to fulfill the requirements of the existence of the convergence conditions for the sliding mode the following expression should be verified [32]:

$S(x) \dot{S}(x) \leq 0$.

\subsubsection{Determination of the control law}

The sliding mode controller structure consists of two parts, one for exact linearization $\left(U_{e q}\right)$ and the other for stability $\left(U_{n}\right)$ [33]. Accordingly, the control algorithm is described as follows:

$U=U_{e q}+U_{n}$.

$U_{e q}$ represents the equivalent control which serves to maintain the variable to be controlled on the sliding surface $S(x)=0$. It can be defined considering that the derivative of the surface is zero $\dot{S}(x)=0$.

$U_{n}$ presents the discrete control, which is used to ensure the convergence condition even under the presence of the imprecision on the parameters of the system model.

The simplest form that the discrete control can take is that of a sign function. However, this kind of function generates on the sliding surface some ripples, which are known as the phenomenon of chattering. It is generally 
undesirable because it adds to the spectrum of the control high frequency components $[34,35]$. Therefore, for the elimination of the chattering, the sign function can be replaced by an adequate saturation function that allows the filtering of the high frequency components found in the control spectrum. The definition of the saturation function $\operatorname{Sat}(t)$ is given as follows:

$\operatorname{Sat}(t)=\frac{S}{|S|+m}$.

with: $m$ is small parameter.

\subsection{Application of SMC on DSIM and DOEWIM}

The synthesis of the control laws of sliding mode control, which will be applied to the DSIM motor with a classical topology and open stators windings topology, is based on the decoupled model obtained by the FOC method. Hence, the system presenting the state is given as follows:

$$
\begin{aligned}
& \left\{\dot{I}_{s d 1}=\frac{1}{L_{s 1}}\left\{+\omega_{s}^{*}\left(\begin{array}{c}
\left.V_{s d 1}-R_{s 1} I_{s d 1} I_{s q 1}+\frac{L_{r}}{R_{r}} \varphi_{r}^{*} \omega_{g l}^{*}\right)
\end{array}\right\}\right.\right. \\
& \dot{I}_{s q 1}=\frac{1}{L_{s 1}}\left\{\begin{array}{c}
V_{s q 1}-R_{s 1} I_{s q 1} \\
+\omega_{s}^{*}\left(L_{s 1} I_{s d 1}+\varphi_{r}^{*}\right)
\end{array}\right\} \\
& \left\{\dot{I}_{s d 2}=\frac{1}{L_{s 2}}\left\{+\omega_{s}^{*}\left(L_{s 2} I_{s q 2}+\frac{L_{r}}{R_{r}} \varphi_{r}^{*} \omega_{g l}^{*}\right)\right\}\right. \text {, } \\
& \dot{I}_{s q 2}=\frac{1}{L_{s 2}}\left\{\begin{array}{c}
V_{s q 2}-R_{s 2} I_{s q 2} \\
+\omega_{s}^{*}\left(L_{s 2} I_{s d 2}+\varphi_{r}^{*}\right)
\end{array}\right\} \\
& \dot{\varphi}_{r}=-\frac{R_{r}}{L_{r}+L_{m}} \varphi_{r}+\frac{R_{r} L_{m}}{L_{r}+L_{m}}\left(I_{s q 1}+I_{s d 2}\right) \\
& \dot{\omega}_{r}=\frac{1}{J}\left\{\begin{array}{c}
P^{2} \frac{L_{m}}{L_{m}+L_{r}} \varphi_{r}^{*}\left(I_{s q 1}+I_{s q 2}\right) \\
-P T_{L}-K_{f} \omega_{r}
\end{array}\right\}
\end{aligned}
$$

where:

*(exhibitor): reference value;

.(exhibitor): derived value;

$\omega_{r}$ : fundamental electrical pulsation of rotor quantities;

$\omega_{s}$ : fundamental electrical pulsation of stator quantities;

$\omega_{g l}:$ fundamental electrical pulsation of sliding.

\subsubsection{Application of sliding mode control on the DSIM}

The control of the DSIM based on SMC will focus mainly of the control of the three variables such as the rotor speed, the rotor flux and the stator currents. The main idea process of such control is presented in the following sub-sections for the three aforementioned variables, respectively.

The speed surface control

The speed regulation surface whose relative degree $r=1$ is of the following form:

$S\left(\omega_{r}\right)=\omega_{r}^{*}-\omega_{r}$.

The derivative of Eq. (17) is obtained as follows:

$\dot{S}\left(\omega_{r}\right)=\dot{\omega}_{r}^{*}-\dot{\omega}_{r}$.

By introducing the equation of $\dot{\omega}_{r}$ Eq. (16) into Eq. (18), Eq. (19) is obtained:

$\dot{S}\left(\omega_{r}\right)=\dot{\omega}_{r}^{*}-\frac{P^{2}}{J} \frac{L_{m}}{L_{m}+L_{r}}\left(I_{s q 1}+I_{s q 2}\right) \varphi_{r}^{*}+\frac{K_{f}}{J} \omega_{r}+\frac{P}{J} T_{L}$.

Assuming that:

$I_{s q 1}+I_{s q 2}=I_{s q}$,

and taking into account that:

$I_{s q}=I_{s q}^{*}=I_{s q e q}+I_{s q n}$.

Using Eqs. (19)-(22) is obtained as follows:

$\dot{S}\left(\omega_{r}\right)=\dot{\omega}_{r}^{*}-\frac{P^{2}}{J} \frac{L_{m}}{L_{m}+L_{r}} \varphi_{r}^{*} I_{s q e q}-\frac{P^{2}}{J} \frac{L_{m}}{L_{m}+L_{r}} \varphi_{r}^{*} I_{s q n}$

$+\frac{K_{f}}{J} \omega_{r}+\frac{P}{J} T_{L}$.

Based on the explanation given after Eq. (14), the equivalent control can be obtained from Eq. (22) as follows:

$$
I_{q e q}=\frac{J}{P^{2}} \frac{L_{m}+L_{r}}{L_{m} \varphi_{r}^{*}}\left\{\dot{\omega}_{r}^{*}+\frac{K_{f}}{J} \omega_{r}+\frac{P}{J} T_{L}\right\} .
$$

The discrete control can be obtained based on the chosen function as follows:

$I_{q n}=K_{\omega_{r}} \frac{S\left(\omega_{r}\right)}{\left|S\left(\omega_{r}\right)+\xi_{\omega_{r}}\right|}$,

where $K_{\omega_{r}}, \xi_{\omega_{r}}$ are positives constants.

The gain $K$ is chosen positive to satisfy the condition (Eq. (13)). The choice of this gain is very influential, because, if it is very small the response time will be very long and therefore reducing the system robustness, and if it is chosen very large, we will have broadened the chattering effect in the control unit.

In this article, we have relied on the Reaching Law (RL) to determine the $k$ value, in particular the reach approach with a potency rate, which is given as follows: 
$\dot{S}=-k|S|^{\alpha} \operatorname{sign}(S)$

with: $0<\alpha<1$.

The control of the rotor flux surface

The rotor flux surface is considered to have the same form as the speed:

$S\left(\varphi_{r}\right)=\varphi_{r}^{*}-\varphi_{r}$.

Its derivative is obtained as follows:

$\dot{S}\left(\varphi_{r}\right)=\dot{\varphi}_{r}^{*}-\dot{\varphi}_{r}$.

By substituting the expression of $\dot{\varphi}_{r}$ in Eq. (27), the derivative of the rotor flux surface can be rewritten as follows:

$\dot{S}\left(\varphi_{r}\right)=\dot{\varphi}_{r}^{*}+\frac{R_{r}}{L_{r}+L_{m}} \varphi_{r}-\frac{R_{r} L_{m}}{L_{r}+L_{m}}\left(I_{s d 1}+I_{s d 2}\right)$,

taking:

$I_{s d 1}+I_{s d 2}=I_{s d}$,

and:

$I_{s d}=I_{s d}^{*}=I_{s d e q}+I_{s d n}$.

Hence Eq. (28) can be re-expressed taking into account Eqs. (29) and (30):

$\dot{S}\left(\varphi_{r}\right)=\dot{\varphi}_{r}^{*}+\frac{R_{r}}{L_{r}+L_{m}} \varphi_{r}-\frac{R_{r} L_{m}}{L_{r}+L_{m}} I_{s d e q}-\frac{R_{r} L_{m}}{L_{r}+L_{m}} I_{s d n}$.

By applying sliding mode theory, the two Eqs. (32) and (33) can be obtained, which represent, respectively the equivalent control and the discrete control:

$I_{d e q}=\frac{L_{r}+L_{m}}{R_{r} L_{m}}\left\{\dot{\varphi}_{r}^{*}+\frac{R_{r}}{L_{r}+L_{m}} \varphi_{r}\right\}$,

$I_{d n}=K_{\varphi_{r}} \frac{S\left(\varphi_{r}\right)}{\left|S\left(\varphi_{r}\right)+\xi_{\varphi_{r}}\right|}$,

where $K_{\varphi_{r}}, \xi_{\varphi_{r}}$ are positives constants.

The control of the surface of the stator currents

We take the following surfaces for all the four stator current components as follows:

$$
\begin{aligned}
& S\left(I_{s d 1}\right)=I_{s d 1}^{*}-I_{s d 1}, \\
& S\left(I_{s q 1}\right)=I_{s q 1}^{*}-I_{s q 1}, \\
& S\left(I_{s d 2}\right)=I_{s d 2}^{*}-I_{s d 2}, \\
& S\left(I_{s q 2}\right)=I_{s q 2}^{*}-I_{s q 2} .
\end{aligned}
$$

Their derivatives can be represented as follows, respectively:

$$
\begin{aligned}
& \dot{S}\left(I_{s d 1}\right)=\dot{I}_{s d 1}^{*}-\dot{I}_{s d 1}, \\
& \dot{S}\left(I_{s q 1}\right)=\dot{I}_{s q 1}^{*}-\dot{I}_{s q 1}, \\
& \dot{S}\left(I_{s d 2}\right)=\dot{I}_{s d 2}^{*}-\dot{I}_{s d 2}, \\
& \dot{S}\left(I_{s q 2}\right)=\dot{I}_{s q 2}^{*}-\dot{I}_{s q 2} .
\end{aligned}
$$

By substituting the expressions of the stator currents derivatives $\left(\dot{I}_{s d 1}, \dot{I}_{s q 1}, \dot{I}_{s d 2}\right.$ and $\left.\dot{I}_{s q 2}\right)$, which have been presented in the state system given in Eq. (16), the derivative of the surfaces can be re-expressed as follows:

$\dot{S}\left(I_{s d 1}\right)=I_{s d 1}^{*}-\frac{1}{L_{s 1}}\left\{+\omega_{s}^{*}\left(\begin{array}{c}-R_{s 1} I_{s d 1} \\ \left.L_{s 1} I_{s q 1}+\tau_{r} \varphi_{r}^{*} \omega_{g l}^{*}\right) \\ +V_{s d 1}\end{array}\right\}\right.$,

$\dot{S}\left(I_{s q 1}\right)=I_{s q 1}^{*}-\frac{1}{L_{s 1}}\left\{\begin{array}{c}-R_{s 1} I_{s q 1} \\ -\omega_{s}^{*}\left(L_{s 1} I_{s d 1}+\varphi_{r}^{*}\right) \\ +V_{s q 1}\end{array}\right\}$,

$\left.\dot{S}\left(I_{s d 2}\right)=I_{s d 2}^{*}-\frac{1}{L_{s 2}}\left\{\begin{array}{c}-R_{s 2} I_{s d 2} \\ +\omega_{s}^{*}\left(L_{s 2} I_{s q 2}+\tau_{r} \varphi_{r}^{*} \omega_{g l}^{*}\right) \\ +V_{s d 2}\end{array}\right)\right\}$,

$\dot{S}\left(I_{s q 2}\right)=I_{s q 2}^{*}-\frac{1}{L_{s 2}}\left\{\begin{array}{c}-R_{s 2} I_{s q 2} \\ -\omega_{s}^{*}\left(L_{s 2} I_{s d 2}+\varphi_{r}^{*}\right) \\ +V_{s q 2}\end{array}\right\}$.

We assume that:

$$
\begin{aligned}
& V_{s d 1}=V_{s d 1}^{*}=V_{s d 1 e q}+V_{s d 1 n}, \\
& V_{s q 1}=V_{s q 1}^{*}=V_{s q 1 e q}+V_{s q 1 n}, \\
& V_{s d 2}=V_{s d 2}^{*}=V_{s d 2 e q}+V_{s d 2 n}, \\
& V_{s q 2}=V_{s q 2}^{*}=V_{s q 2 e q}+V_{s q 2 n} .
\end{aligned}
$$

By substituting Eqs. (46)-(49) in Eqs. (42)-(45), respectively, the derivatives can be rewritten as follows:

$$
\dot{S}\left(I_{s d 1}\right)=I_{s d 1}^{*}-\frac{1}{L_{s 1}}\left\{\begin{array}{c}
-R_{s 1} I_{s d 1} \\
+\omega_{s}^{*}\left(L_{s 1} I_{s q 1}+\tau_{r} \varphi_{r}^{*} \omega_{g l}^{*}\right) \\
+V_{s d 1 e q}+V_{s d 1 n}
\end{array}\right\},
$$




$$
\begin{aligned}
& \dot{S}\left(I_{s q 1}\right)=I_{s q 1}^{*}-\frac{1}{L_{s 1}}\left\{\begin{array}{c}
-R_{s 1} I_{s q 1} \\
-\omega_{s}^{*}\left(L_{s 1} I_{s d 1}+\varphi_{r}^{*}\right) \\
+V_{s q 1 e q}+V_{s q 1 n}
\end{array}\right\}, \\
& \dot{S}\left(I_{s d 2}\right)=I_{s d 2}^{*}-\frac{1}{L_{s 2}}\left\{\begin{array}{c}
-R_{s 2} I_{s d 2} \\
+\omega_{s}^{*}\left(L_{s 2} I_{s q 2}+\tau_{r} \varphi_{r}^{*} \omega_{g l}^{*}\right) \\
+V_{s d 2 e q}+V_{s d 2 n}
\end{array}\right\}, \\
& \dot{S}\left(I_{s q 2}\right)=I_{s q 2}^{*}-\frac{1}{L_{s 2}}\left\{\begin{array}{c}
-R_{s 2} I_{s q 2} \\
-\omega_{s}^{*}\left(L_{s 2} I_{s d 2}+\varphi_{r}^{*}\right) \\
+V_{s q 2 e q}+V_{s q 2 n}
\end{array}\right\} .
\end{aligned}
$$

Finally, by applying sliding mode theory, the two groups of equations can be obtained, which represent, respectively the decoupling control voltages (which represent the equivalent control in Eqs. (54)-(57) and the switching control voltages (which represent the discrete control in Eqs. (58)-(61)).

$$
\begin{aligned}
& V_{s d 1 e q}=L_{s 1} I_{s d 1}^{*}+R_{s 1} I_{s d 1}-\omega_{s}^{*}\left\{L_{s 1} I_{s q 1}+\tau_{r} \varphi_{r}^{*} \omega_{g l}^{*}\right\}, \\
& V_{s q l e q}=L_{s 1} I_{s q 1}^{*}+R_{s 1} I_{s q 1}+\omega_{s}^{*}\left\{L_{s 1} I_{s d 1}+\varphi_{r}^{*}\right\}, \\
& V_{s d 2 e q}=L_{s 2} I_{s d 2}^{*}+R_{s 2} I_{s d 2}-\omega_{s}^{*}\left\{L_{s 2} I_{s q 2}+\tau_{r} \varphi_{r}^{*} \omega_{g l}^{*}\right\}, \\
& V_{s q 2 e q}=L_{s 2} I_{s q 2}^{*}+R_{s 2} I_{s q 2}+\omega_{s}^{*}\left\{L_{s 2} I_{s d 2}+\varphi_{r}^{*}\right\}, \\
& V_{s d 1 n}=K_{I_{s d 1}} \frac{S\left(I_{s d 1}\right)}{S\left(I_{s d 1}\right)+\xi_{I_{s d 1}}}, \\
& V_{s q 1 n}=K_{I_{s q 1}} \frac{S\left(I_{s q 1}\right)}{S\left(I_{s q 1}\right)+\xi_{I_{s q 1}}},
\end{aligned}
$$

$$
\begin{aligned}
& V_{s d 2 n}=K_{I_{s d 2}} \frac{S\left(I_{s d 2}\right)}{S\left(I_{s d 2}\right)+\xi_{I_{s d 2}}}, \\
& V_{s q 2 n}=K_{I_{s q 2}} \frac{S\left(I_{s q 2}\right)}{S\left(I_{s q 2}\right)+\xi_{I_{s q 2}}},
\end{aligned}
$$

where $K_{I_{s d 1}}, \xi_{I_{s d 1}}, K_{I_{s q 1}}, \xi_{I_{s q 1}}, K_{I_{s d 2}}, \xi_{I_{s d 2}}$, and $K_{I_{s q 2}}, \xi_{I_{s q 2}}$ are positives constants.

Fig. 7 gives the general diagram of the control structure by sliding mode of a DSIM supplied by two three-phase inverters and controlled in speed, rotor flux and stator currents in a non-linear control plane. This control technique is combined with the SVPWM for the purpose of achieving high performance.

\subsubsection{Application of sliding mode control on DOEWIM}

For the application of the sliding mode control on DOEWIM, the same steps as the one used in Sub-subsection 4.2.1 will be used here for the determination of the different control surfaces for the three variables such as the rotor speed, the rotor flux and the stator currents, where the main aim is to obtain finally the two components of the surface control such as the equivalent control and the discrete control.

The speed surface control

The equivalent control and the discrete control for the rotor speed surface are obtained as follows:

$$
\begin{aligned}
& I_{q e q}=\frac{J}{3 P^{2}} \frac{L_{m}+L_{r}}{L_{m} \varphi_{r}^{*}}\left\{\dot{\omega}_{r}^{*}+\frac{K_{f}}{J} \omega_{r}+\frac{2 P}{J} T_{L}\right\}, \\
& I_{q n}=K_{\omega_{r}}^{\prime} \frac{S\left(\omega_{r}\right)}{S\left(\omega_{r}\right)+\xi_{\omega_{r}}^{\prime}},
\end{aligned}
$$

where $K_{\omega_{r}}^{\prime}, \xi_{\omega_{r}}^{\prime}$ are positives constants.

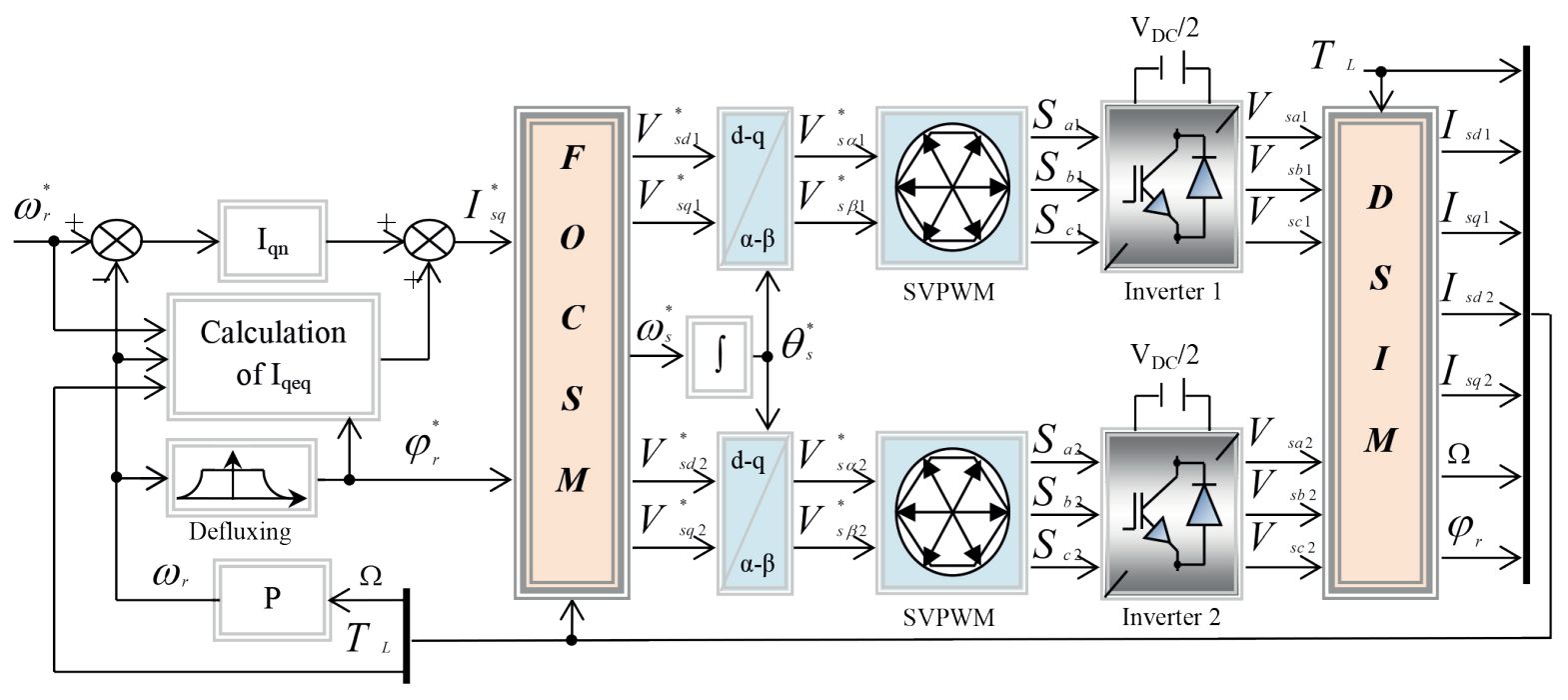

Fig. 7 The sliding mode control scheme applied on DSIM 
The control of the rotor flux surface

With similar process, the equivalent control and the discrete control of the rotor flux surface of the DOEWIM can be obtained as follows:

$$
\begin{aligned}
& I_{d e q}=\frac{L_{r}+L_{m}}{R_{r} L_{m}}\left\{\dot{\varphi}_{r}^{*}+\frac{R_{r}}{L_{r}+L_{m}} \varphi_{r}\right\}, \\
& I_{d n}=K_{\varphi_{r}}^{\prime} \frac{S\left(\varphi_{r}\right)}{S\left(\varphi_{r}\right)+\xi_{\varphi_{r}}^{\prime}},
\end{aligned}
$$

where $K_{\varphi_{r}}^{\prime}, \xi_{\varphi_{r}}^{\prime}$ are positives constants.

We can note here that the two control components are the same as for the case of DSIM.

The control of the surface of the stator currents

With the same process the components of the equivalent control and the discrete control of the stator currents surfaces are obtained as follows:

$V_{s d 11 e q}-V_{s d 12 e q}=-\omega_{s}^{*}\left\{L_{s 1} I_{s q 1}+\tau_{r} \varphi_{r}^{*} \omega_{g l}^{*}\right\}+L_{s 1} I_{s d 1}^{*}+R_{s 1} I_{s d 1}$,

$V_{s q 11 e q}-V_{s q 12 e q}=\omega_{s}^{*}\left\{L_{s 1} I_{s d 1}+\varphi_{r}^{*}\right\}+L_{s 1} I_{s q 1}^{*}+R_{s 1} I_{s q 1}$,

$V_{s d 21 e q}-V_{s d 22 e q}=-\omega_{s}^{*}\left\{L_{s 2} I_{s q 2}+\tau_{r} \varphi_{r}^{*} \omega_{g l}^{*}\right\}$

$+L_{s 2} I_{s d 2}^{*}+R_{s 2} I_{s d 2}$

$V_{s q 21 e q}-V_{s q 22 e q}=\omega_{s}^{*}\left\{L_{s 2} I_{s d 2}+\varphi_{r}^{*}\right\}+L_{s 2} I_{s q 2}^{*}+R_{s 2} I_{s q 2}$,

$V_{s d 11 n}=V_{s d 12 n}=K_{I_{s d 1}}^{\prime} \frac{S\left(I_{s d 1}\right)}{S\left(I_{s d 1}\right)+\xi_{I_{s d 1}}^{\prime}}$,

$$
\begin{aligned}
& V_{s q 11 n}=V_{s q 12 n}=K_{I_{s q 1}}^{\prime} \frac{S\left(I_{s q 1}\right)}{S\left(I_{s q 1}\right)+\xi_{I_{s q 1}}^{\prime}}, \\
& V_{s d 21 n}=V_{s d 22 n}=K_{I_{s d 2}}^{\prime} \frac{S\left(I_{s d 2}\right)}{S\left(I_{s d 2}\right)+\xi_{I_{s d 2}}^{\prime}}, \\
& V_{s q 21 n}=V_{s q 22 n}=K_{I_{s q 2}}^{\prime} \frac{S\left(I_{s q 2}\right)}{S\left(I_{s q 2}\right)+\xi_{I_{s q 2}}^{\prime}},
\end{aligned}
$$

where $K_{I_{s d 1}}^{\prime}, \xi_{I_{s d 1}}^{\prime}, K_{I_{s q 1}}^{\prime}, \xi_{I_{s q 1}}^{\prime}, K_{I_{s d 2}}^{\prime}, \xi_{I_{s d 2}}^{\prime}$, and $K_{I_{s q 2}}^{\prime}, \xi_{I_{s q 2}}^{\prime}$ are positives constants.

We cannot here that these components are similar to those obtained with the DSIM, except that each equivalent component is presenting the differences between the equivalent components of the voltages applied in each side of the winding.

Fig. 8 shows the structure of the same control technique associated with the SVPWM and which was shown in Fig. 7, but in this figure, it is applied on the DOEWIM motor to ensure the control of the same variables as in the previous case. It can be seen clearly in this figure that DOEWIM is supplied by four three phase two-level inverters. Indeed, each inverter is connected to one stator winding end, which are in our case four stator winding ends.

\section{Simulation results and discussions}

In Section 5, the application of the sliding mode control on both three-phase topologies of Dual Star Induction Machine (DSIM) and Dual Open-End Winding Induction Machine (DOEWIM) have been carried out under simulation tests,

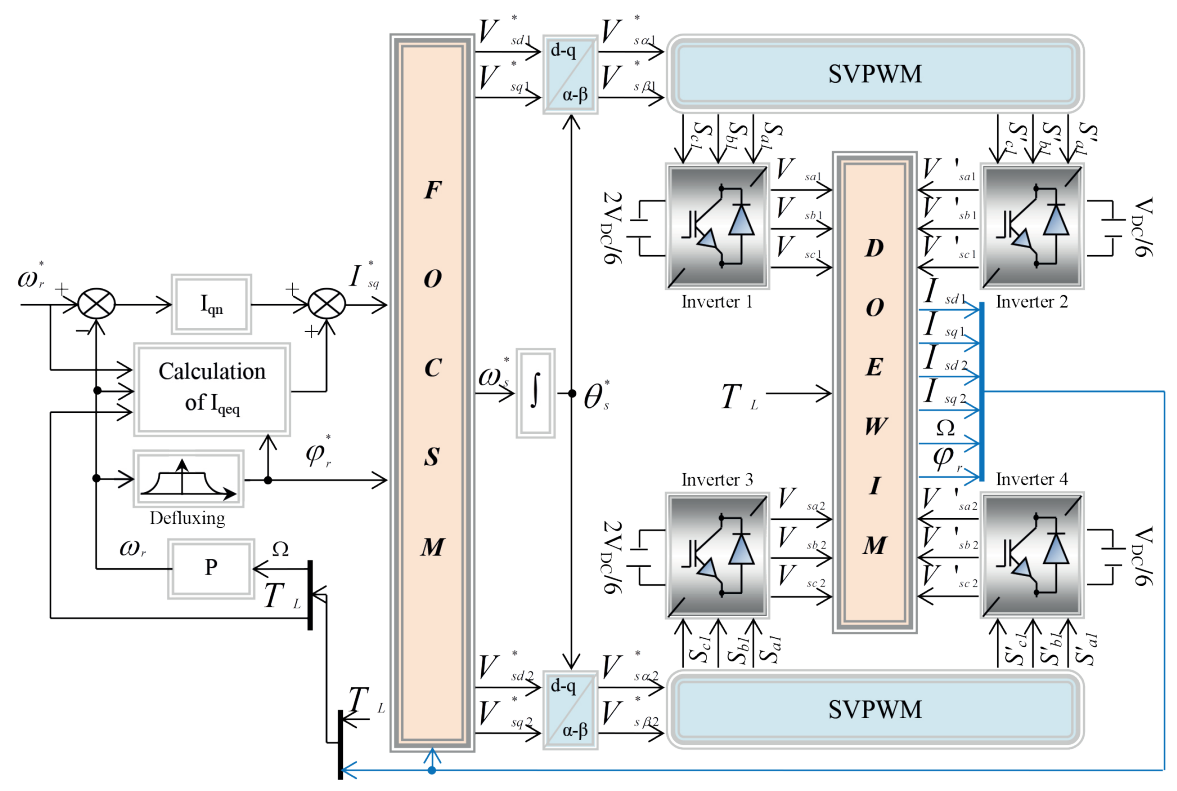

Fig. 8 The sliding mode control scheme applied on DOEWIM 
where the same machine with the characteristics given in the Appendix, has been used for these tests.

The main objective of this simulation is to present a detailed comparison between both topologies performances based on the analysis of the dynamic behavior of the chosen electrical, electromagnetic and mechanical variables subject of the proposed control such as stator current, electromagnetic torque, rotor flux and rotor speed. For such purpose two main operating mode tests have been performed for both topologies under similar operating conditions and same controller parameters. The first one has been performed 50\% of motor rated speed operation taking into account the steps of starting up under no load, load torque application and speed reverse. The second one has been performed under low-speed operation about 3\% of the motor rated speed under the same operation conditions as in the first test.

\subsection{Normal speed operation}

The simulation of the both topologies DSIM and DOEWIM have been performed under normal speed in steady state which is chosen to be $50 \%$ of the rated speed of the machine in both directions. Indeed, this simulation includes a sequence of steps, which can imitate the practical cases in industrial applications. The machine starts up at $t=0 \mathrm{~s}$ with no load following an imposed reference speed profile, at $t=1.0 \mathrm{~s}$ a load torque of $T_{L}=5 \mathrm{~N} \mathrm{~m}$ is applied that is considered as an external perturbation, at $t=1.5 \mathrm{~s}$ the applied load torque is increased to $T_{L}=10 \mathrm{~N} \mathrm{~m}$, then at $t=2.0 \mathrm{~s}$ the applied load torque is removed which means that $T_{L}=0 \mathrm{~N} \mathrm{~m}$. the second part of this simulation presented the dynamic behavior of the proposed control against the speed revers, where at $t=2.5 \mathrm{~s}$ the reference speed is reverse without the application of any torque load.

The voltage obtained by the two topologies DSIM and DOEWIM are shown in Fig. 9 (a) and (b), respectively.

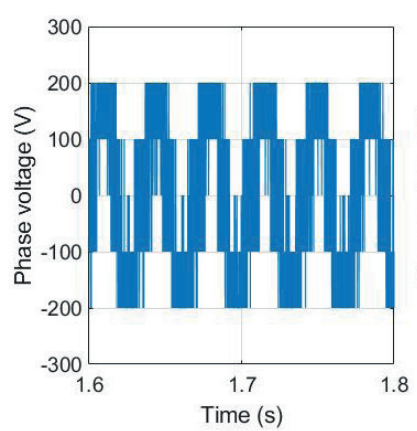

(a)

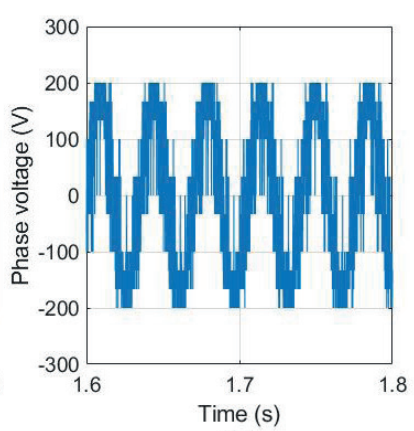

(b)
Fig. 9 The voltage applied on the first stator winding of phase "a"; (a) DSIM, (b) DOEWIM
It is clear that for the case of the DOEWM the voltage applied to each phase winding is seen as if it is power by fourlevel inversion contrary to the topology of DSIM which is powered by two-level inverter, this advantage leads to less rated voltage applied at the used power switches which is nearly reduced to the half due to the fact that the DOEWIM dual inverters are power by a DC voltage which is equal to the half of the DC voltage used at the input side of DSIM topology inverters. Fig. 10 (a) and (b) show the harmonic

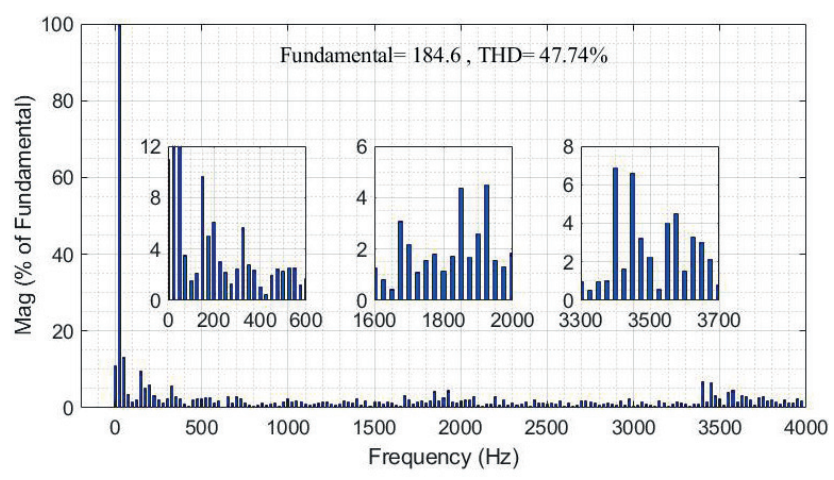

(a)

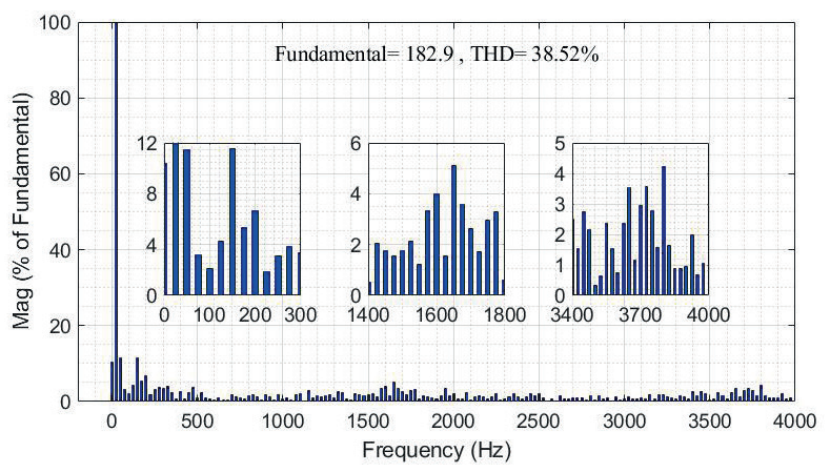

(b)

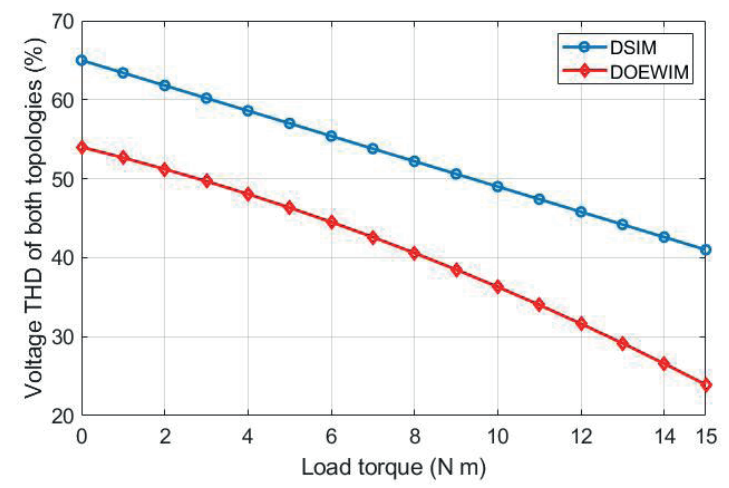

(c)

Fig. 10 (a) The harmonics spectrum of the voltage applied on the first stator winding of DSIM at phase "a", (b) The harmonics spectrum of the voltage applied on the first stator winding of DOEWIM at phase "a",

(c) The voltage harmonics spectrum comparison of both topologies along the variation of the load from non-load to rated load 
spectrum of the obtained voltage at phase 'a' of the first stator winding for the both topologies. It is obvious that in the case of the DSIM the harmonics content is more important with $T H D_{V}=47.74 \%$ in comparison with the case of DOEWIM which is characterized by $T H D_{V}=38.52 \%$. Fig. 10 (c) summarizes a comparison of the evolution of the $T H D_{V}$ in both cases along the load torque variation from zero to the rated torque value which is given by the constructor as presented in Table. 2 (in Appendix), where it is clear that the proposed topology has less $T H D_{V}$ which can contribute positively for obtaining better current quality and less electromagnetic torque ripples.

Fig. 11 (a) and (b) present the dynamic evolution of the reference and the motor rotor speeds of the both topologies, respectively. It can be seen clearly that the rotor speed tracks the reference speed during all the speed profile. It is important to mention here that during the reference speed the speed passes from $N=157 \mathrm{rad} / \mathrm{s}$ to $-N=157 \mathrm{rad} / \mathrm{s}$ in a linear manner which imitates the real practical case. So, it can be said that this dynamic evolution of the speed in comparison with the imposed speed reference is very satisfactory in all aforementioned operating modes within the load torque variation intervals, where there are no impact on the tracking quality of the rotor speed during

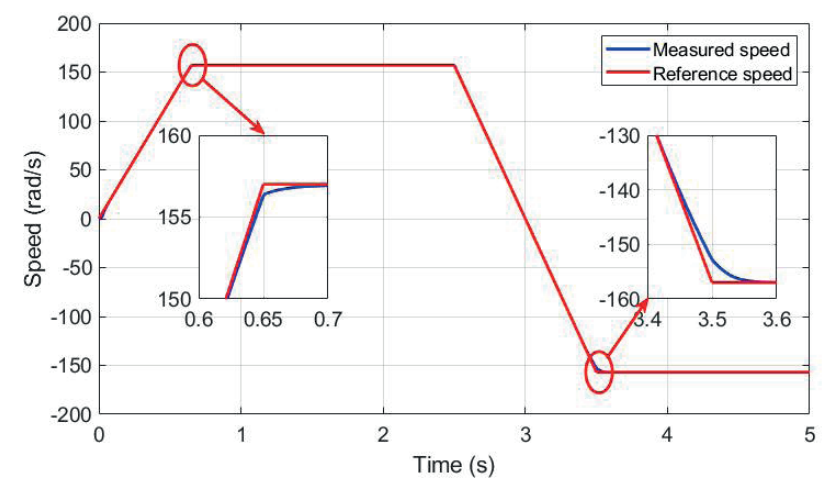

(a)

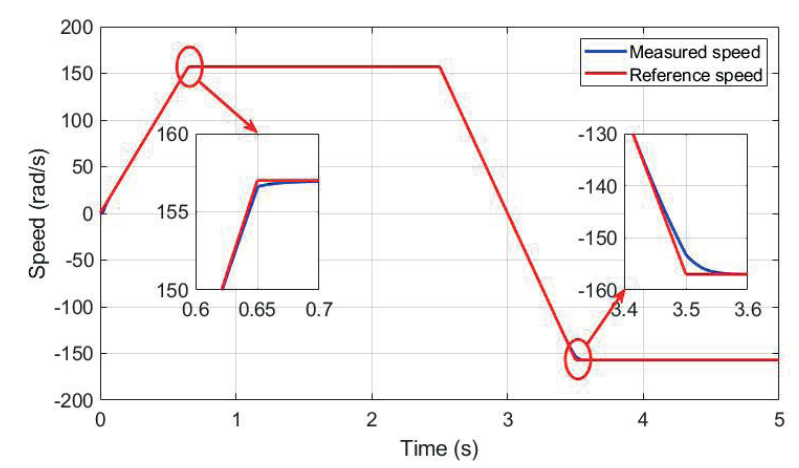

(b)

Fig. 11 (a) The rotor speed of the DSIM topology, (b) The rotor speed of the DOEWIM topology these modes. However, the second topology has relatively faster dynamics in tracking the reference speed with less ripples and less error between the references speed and the developed speed by the machine, especially during start up as shown in the depicted zooms of Fig. 11 (a) and (b).

Fig. 12 (a) and Fig. 13 (a) show the electromagnetic torque $T_{e m}$ developed by both IM topologies, respectively. It is obvious in that in both cases that the $T_{e m}$ tracks the load torque within a very short time of $0.04 \mathrm{~s}$ and $0.05 \mathrm{~s}$ for DOEWIM and DSIM, respectively without any kind of disturbances impact on the quality of the speed as shown in Fig. 11 (a) and (b), on the other side the overshoots of the developed $T_{e m}$ in both cases for different loads are nearly neglected. It is important to clarify that the DSIM and DOEWIM are considered as multi-phase machines where the torque ripples are reduced considerable in comparison of their counter parts three-phase machines. However, the DOEWIM topology presents a very interesting advantages, where the resulting $T_{e m}$ ripple are significantly reduced in comparison to the DSIM topology as it can be noticed clearly in the Fig. 12 (b) and Fig. 13 (b). This advantage allows reducing the mechanical stresses along the shaft and bearings and obtaining less noise and vibrations in the DOEWIM. It is due to the fact that the quality

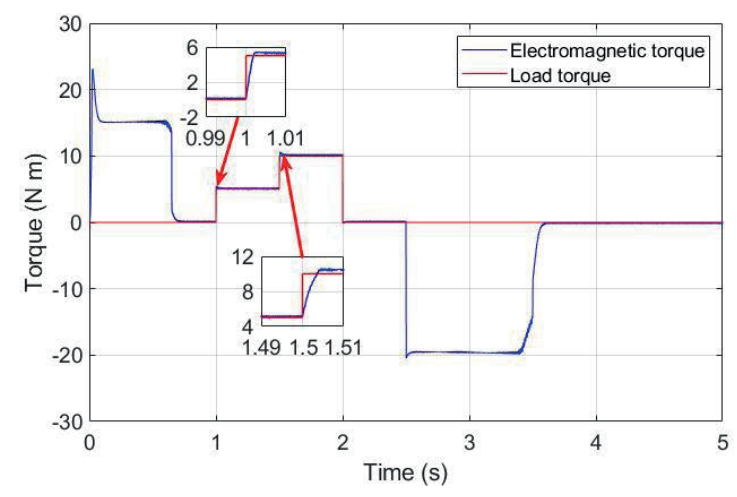

(a)

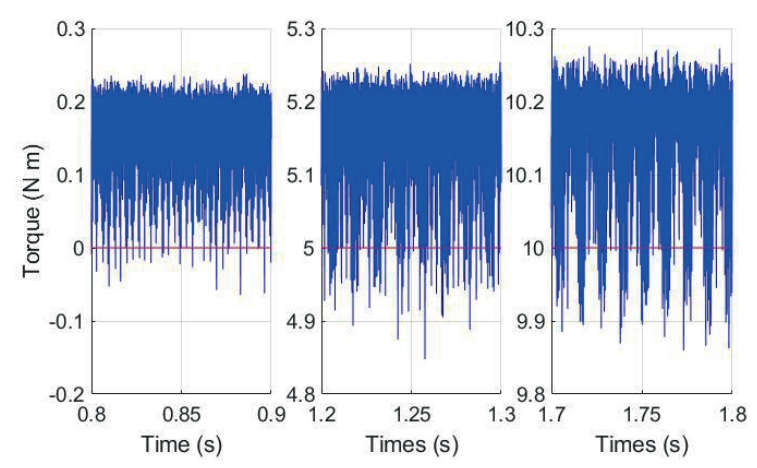

(b)

Fig. 12 (a) The electromagnetic torque developed by the DSIM, (b) Zoom of the electromagnetic torque developed by the DSIM 


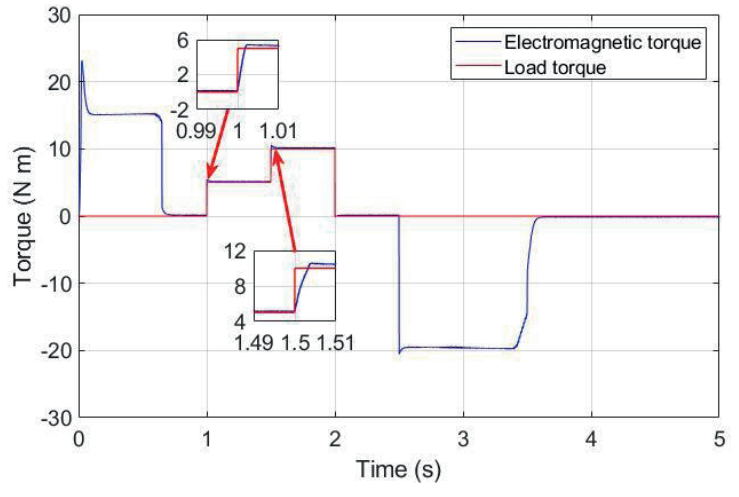

(a)

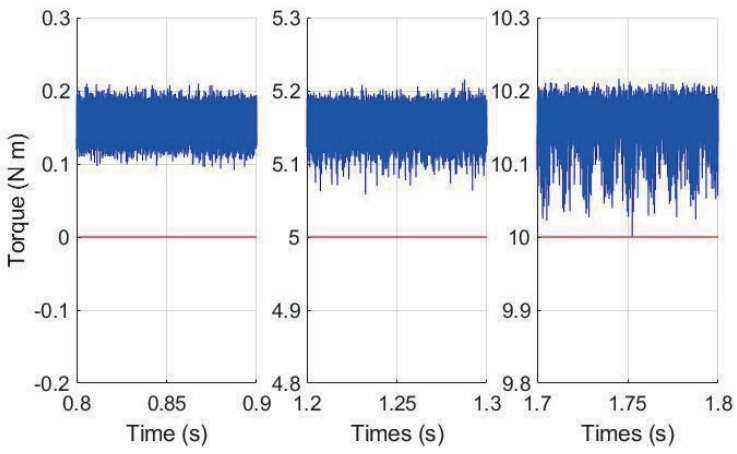

(b)

Fig. 13 (a) The electromagnetic torque developed by the DOEWIM, (b) Zoom of the electromagnetic torque developed by the DOEWIM

of multi-level voltage applied to the winding and the less impact of the chattering phenomenon with the proposed topology DOEWIM compared to the conventional configuration DSIM where the ripples level are more apparent. The non-exact congruence of the load torque and the average value of the developed $T_{e m}$ is due to the difference produced by the relating friction torque which depends essentially on the friction coefficient mentioned in Table 2 (in Appendix) and the motor rotor speed, in the present case this friction torque is $K_{f} . \omega_{r}=0.157 \mathrm{~N} \mathrm{~m}$.

The currents in the three phases of the first stator winding for the two topologies are shown, respectively in Fig. 14 (a) and Fig. 15 (a) along the aforementioned simulation steps. It can be noticed clearly that the start-up peak current and the time for this transition are nearly the same for both topologies. However, a zoom visualization of these currents within three steps with different torque loads such as $T_{L}=0 \mathrm{~N} \mathrm{~m}, T_{L}=5 \mathrm{~N} \mathrm{~m}$ and $T_{L}=10 \mathrm{~N} \mathrm{~m}$ are shown in Fig. 14 (b) and Fig. 15 (b), it can be deduced that the harmonics content is less in the case of open-end winding which lead to a better quality of the stator current and less ripples in the electromagnetic torque. In Fig. 16 many tests have been performed with different load torques ranging from zero to $T_{L}=5 \mathrm{~N} \mathrm{~m}$ where the improved THD of the

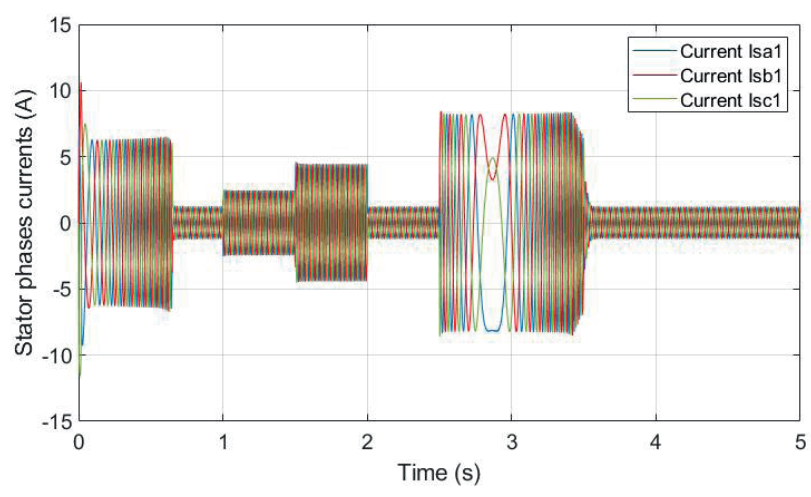

(a)

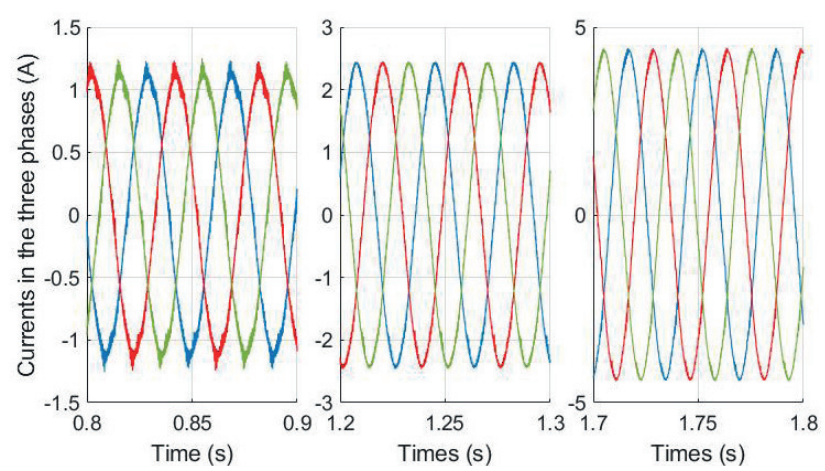

(b)

Fig. 14 (a) The stator phase currents of DSIM, (b) Zoom of the stator phase currents of DSIM

proposed topology is well proved. Indeed, this feature can be considered as one among other advantages of using the DOEWIM topology compared to the conventional topology that may lead to improve the overall performance of the system based on the open-end winding.

Fig. 16 shows the rotor fluxes for the DSIM and DOEWIM topologies following the $d, q$ axis where very satisfactory responses behavior are achieved during the start-up which are characterized by of short duration before reaching the value of $1 \mathrm{~Wb}$ and $0 \mathrm{~Wb}$ for the two rotor flux components following the $d, q$ axis, respectively. On the other side, these results prove that the impacts of the load torque variation and the rotation direction inversion have no influence on the obtained rotor fluxes for both topologies which can be explained by the accurate control of SMC combined with SVPWM applied in this paper for both topologies where its ability of different disturbance rejection is proved clearly. The DOEWIM topology allows us to achieve a significant improvement in the rejection of harmonics in the rotor flux, this can be confirmed by the observation of Fig. 17, which shows that the rotor flux in the DOEWIM topology is improved compared to the DSIM topology. 


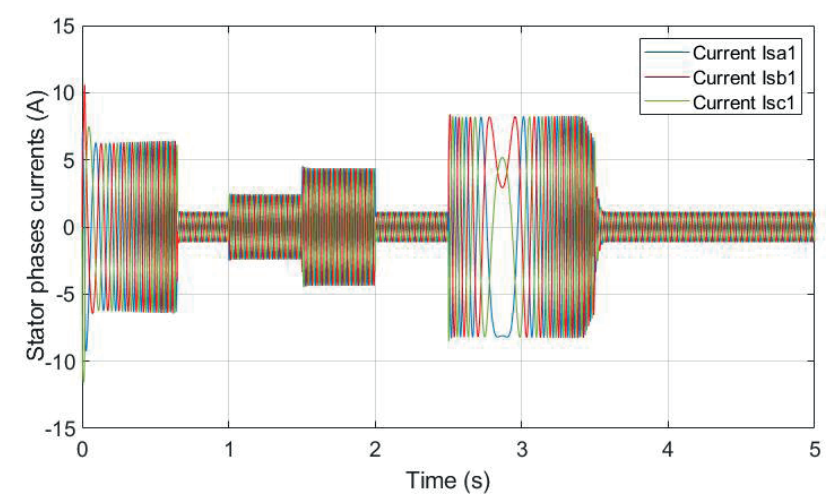

(a)

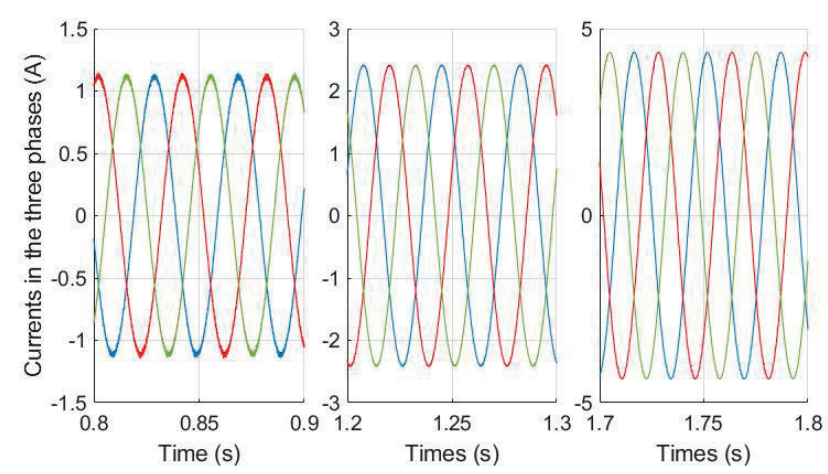

(b)

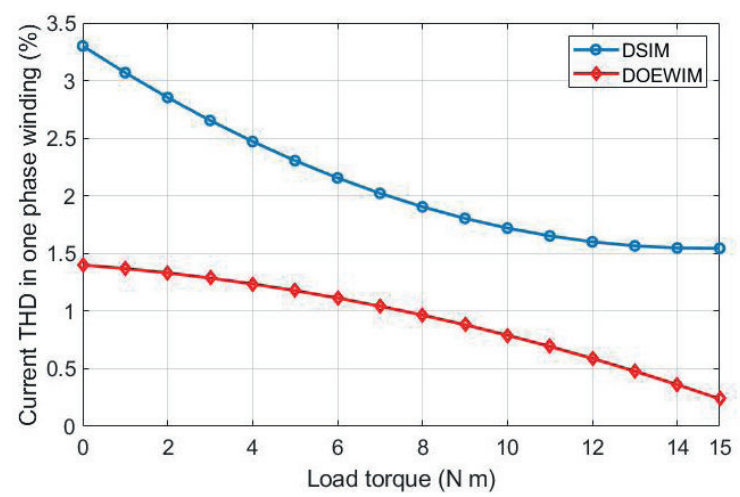

(c)

Fig. 15 (a) The stator phase currents of DOEWIM, (b) Zoom of the stator phase currents of DOEWIM, (c) The current harmonics spectrum comparison of both topologies along the variation of the load from nonload to rated load

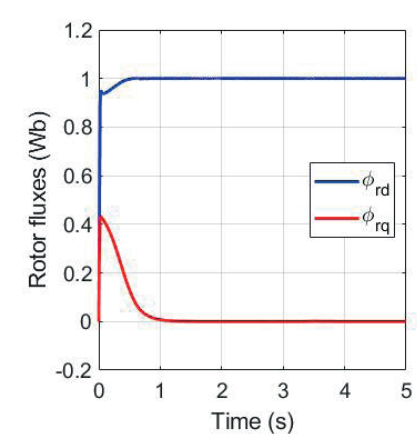

(a)

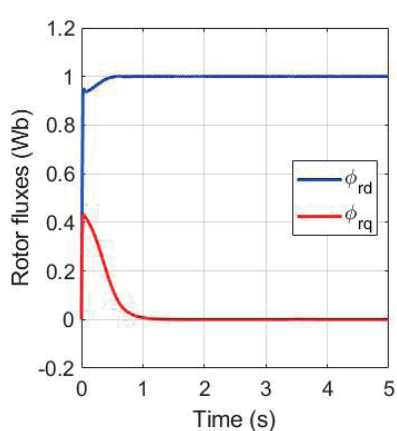

(b)
Fig. 16 The two components of the rotor flux; (a) DSIM, (b) DOEWIM

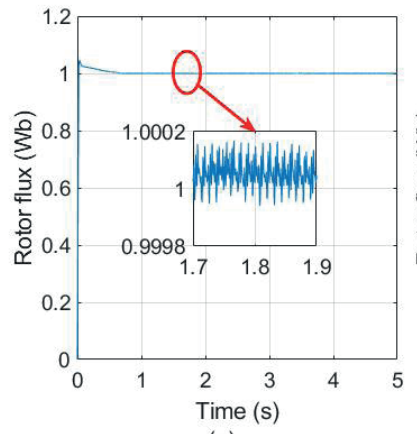

(a)

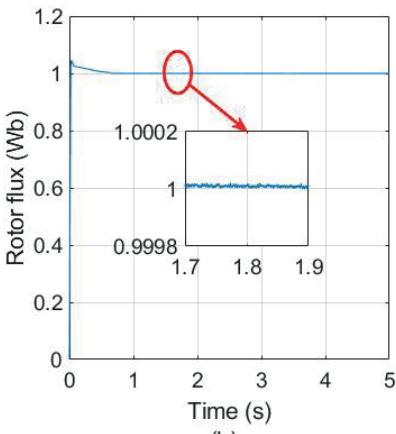

(b)
Fig. 17 The rotor flux: (a) DSIM, (b) DOEWIM

Another important advantage of using the DOEWIM is the elimination of the common mode voltage related to the star point in both stator winding of the DSIM. Indeed, in DOEWIM the star point are cancelled and hence the current circulation in the metallic parts of the motor toward the ground due the CMV is reduced significantly, contrary to the DSIM topology where the two star points give birth to a relatively important difference of potential between the each star point and the ground allowing the generation of stress currents, which contribute drastically for the degradation of some parts of the motor especially in the bearings and the surface contact of shaft with bearings. Fig. 18 (a), (b) and (c) present the CMV spectrum related to the first star point, the second star point and the produced voltage between these two points, respectively. It is well noticed that these voltages are important and can lead to many problems in industrial application when the DSIM topology is used, however with the use of the DOEWIM this problem can be avoided totally.

\subsection{Low speed operation test}

The simulation test of the both topologies DSIM and DOEWIM have been performed under low speed in steady state which is chosen to be under of $3 \%$ of the rated speed of the machine in both directions. In fact, this simulation test was carried out following a set of steps to make deep comparison of the performances under a wide range of speed variation. The first step, the machine starts up at $t=0 \mathrm{~s}$ with no load following an imposed reference speed profile, at $t=0.5 \mathrm{~s}$ a load torque $T_{L}=5 \mathrm{~N} \mathrm{~m}$ is applied, at $t=1.5$ the applied load torque is removed which means that $T_{L}=0 \mathrm{~N}$ m while within the second step of this simulation, the reference speed is reverse at $t=2.0 \mathrm{~s}$ without the application of any torque load to show the dynamic behavior of the proposed control for both topologies against the speed revers. 


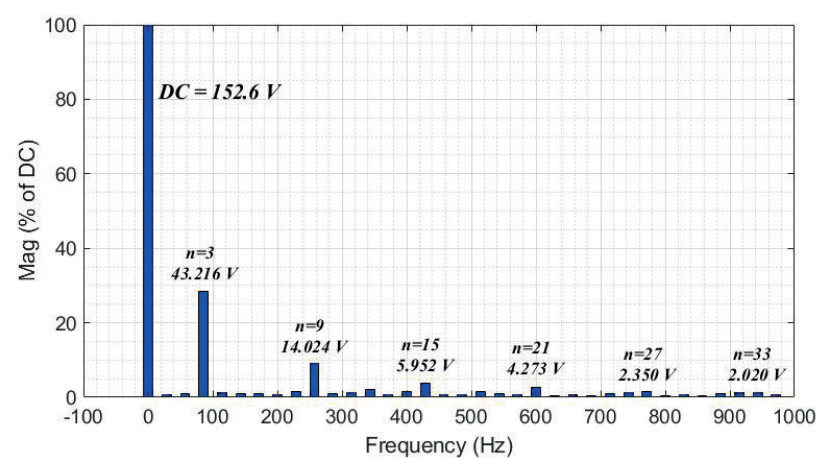

(a)

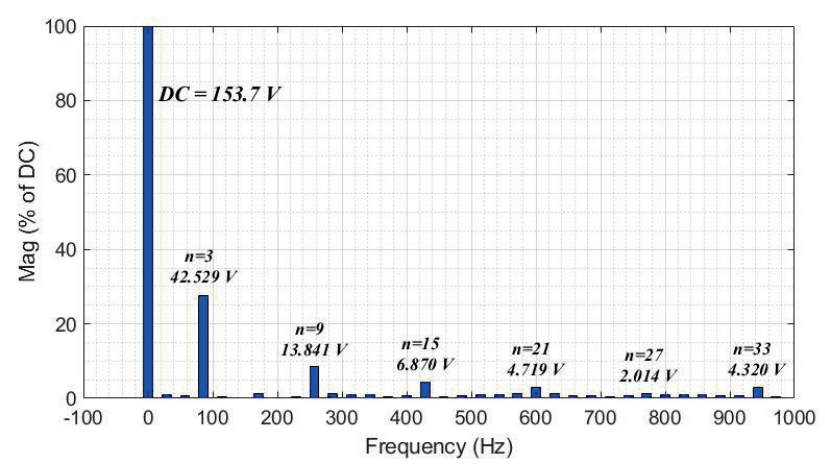

(b)

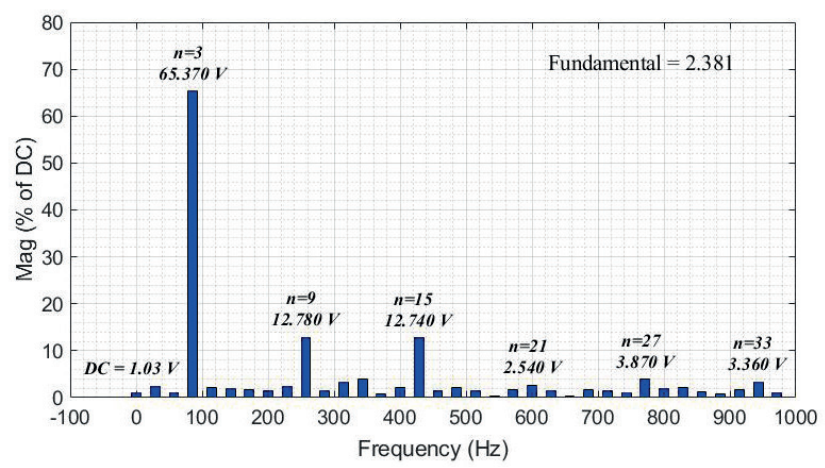

(c)

Fig. 18 (a) The first winding common mode voltage (CMV) of DSIM,

(b) The second winding common mode voltage (CMV) of DSIM,

(c) The common mode voltage (CMV) between the two-star points of the both stator windings of DOEWIM

Fig. 19 (a) and (b) present, respectively the dynamic evolution of the reference and the motor rotor speeds of the DSIM and DOEWIM topologies. It is evident that the rotor speed tracks well the reference speed along the two steps, where the profile of the reference rotor speed passes from $0 \mathrm{rad} / \mathrm{s}$ to $10 \mathrm{rad} / \mathrm{s}$ and then from $10 \mathrm{rad} / \mathrm{s}$ to $-10 \mathrm{rad} / \mathrm{s}$ reflecting the real practical case. Regarding the application of torque or its removal, it can be noted clearly that it does not affect the quality of the tracking of reference rotor speed. But, the second topology has better dynamics in reducing the overshoot value when changing the direction

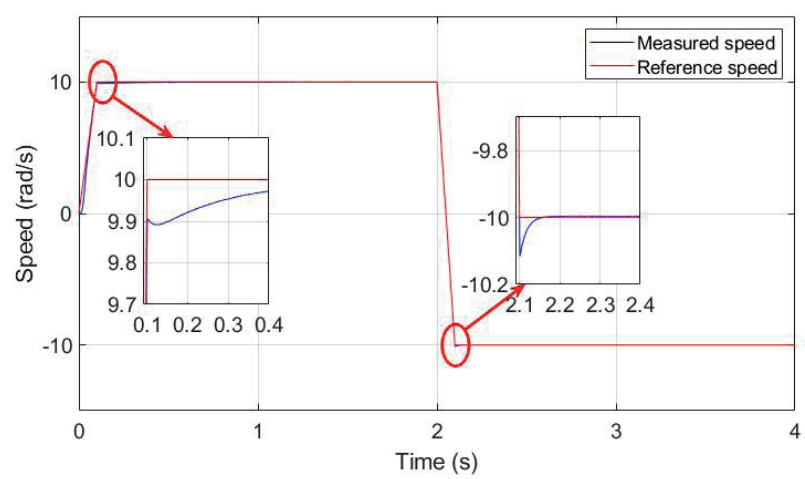

(a)

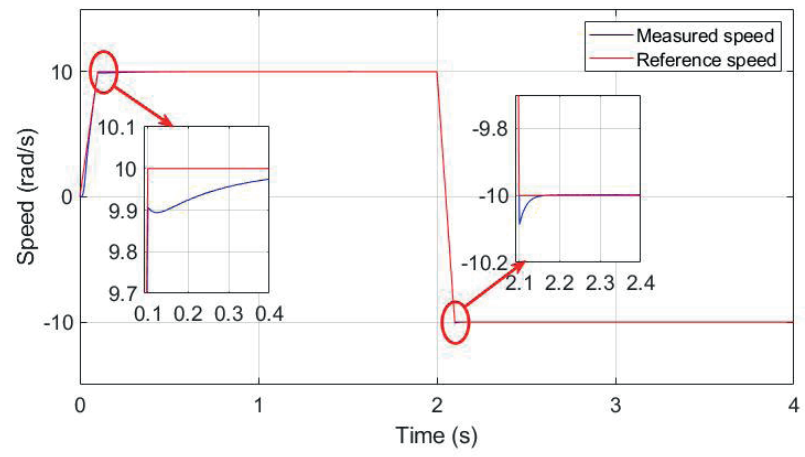

(b)

Fig. 19 (a) The rotor speed of the DSIM topology at low values,

(b) The rotor speed of the DOEWIM topology at low values

of rotation of the machine, making its performance to be better than the first topology, and this is shown clearly in zooms of Fig. 11 (a) and (b).

Fig. 20 (a) and (b) show the electromagnetic torque developed by both IM topologies, respectively. It can be seen that in both cases, the $T_{e m}$ quickly tracks the load torque without any overshoots, and without any kind of disturbances impact on the quality of the speed as shown in Fig. 11 (a) and (b). Whereas, it is clear that the DOEWIM topology presents a very interesting advantages, where the resulting $T_{e m}$ ripple are significantly reduced in comparison to the DSIM topology as it can be noticed in the zoomed parts of Fig. 11 (a) and (b). This makes the new topology a preferred choice to minimize chattering phenomenon even at low speeds.

The phases currents of the first stator winding for the two topologies are shown, respectively in Fig. 21 (a) and Fig. 22 (a). Indeed, it is obvious that these currents in the two configurations are extremely similar in terms of peak current and the current dynamics in transient interval during start up, respectively. However, Fig. 21 (b) and Fig. 22 (b) which represent the zoom visualization of the phase currents during the application and the cancellation of load torque for the two topologies DSIM and DOEWIM, respectively show 


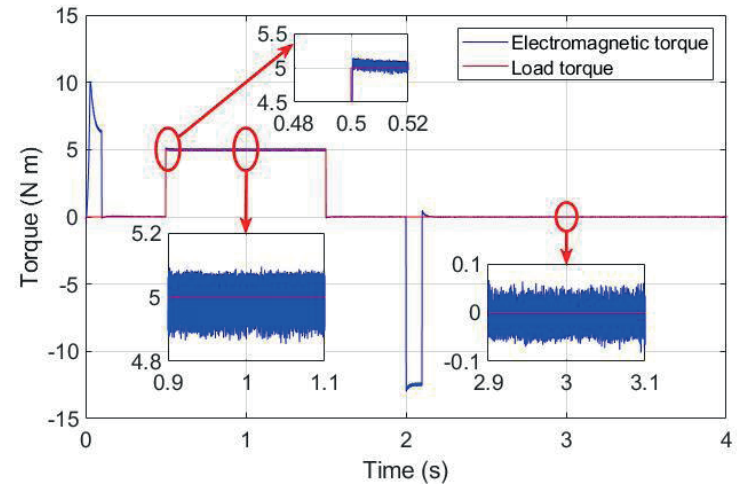

(a)

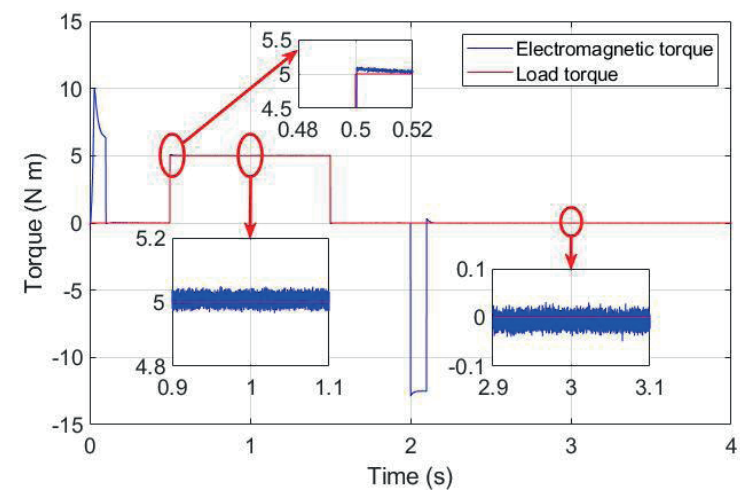

(b)

Fig. 20 (a) The electromagnetic torque developed by the DSIM at low speed, (b) The electromagnetic torque developed by the DOEWIM at low speed

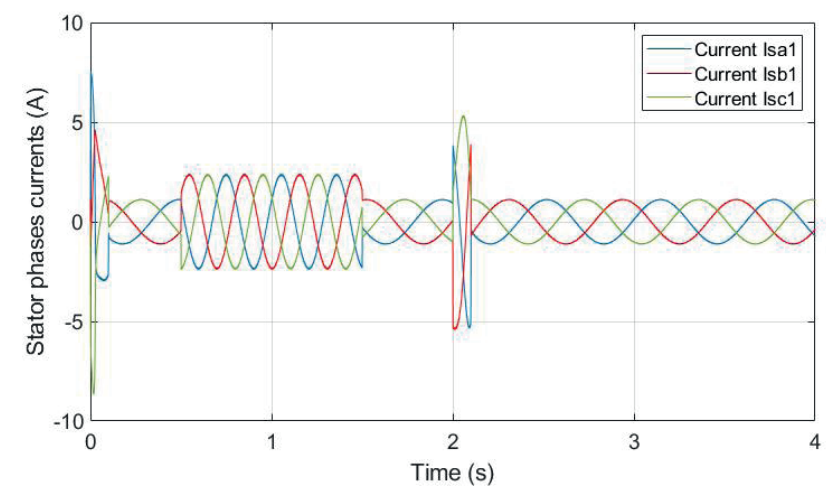

(a)

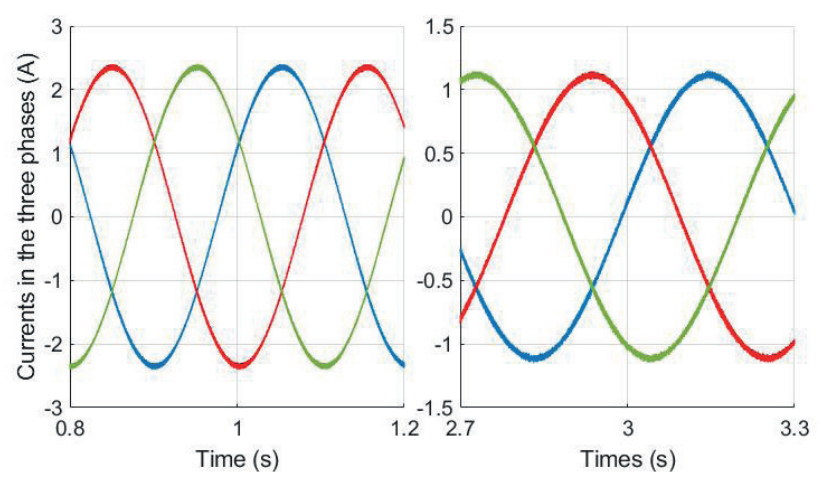

(b)

Fig. 21 (a) The stator phase currents of DSIM at low speed, (b) Zoom of the stator phase currents of DSIM at low speed

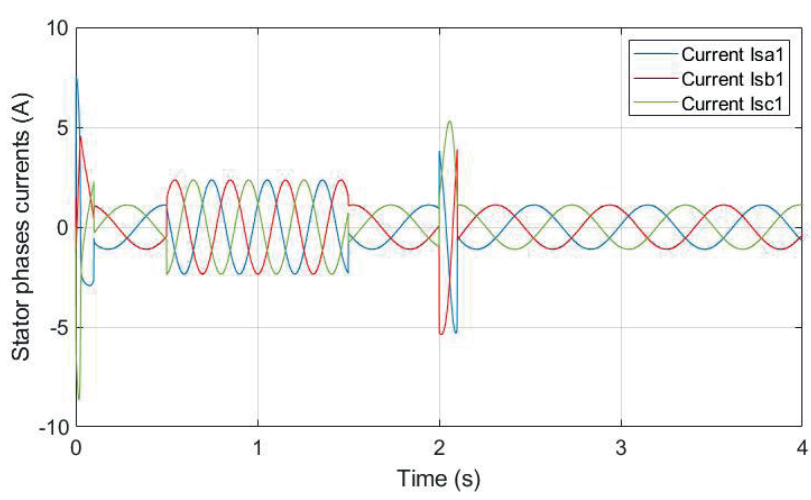

(a)

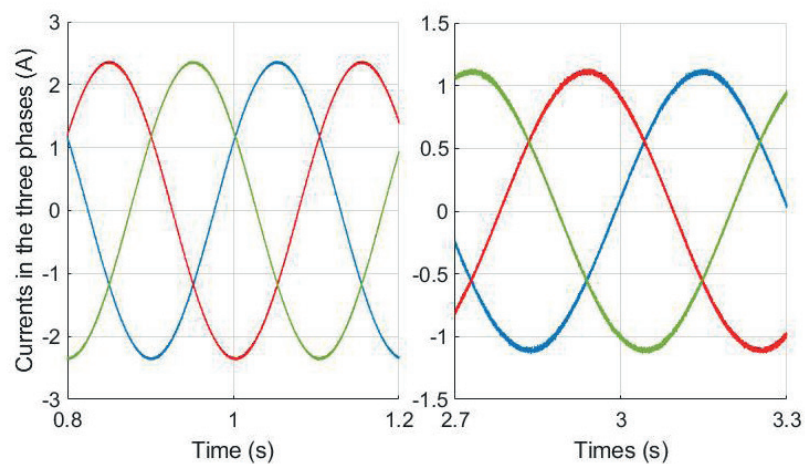

(b)

Fig. 22 (a) Stator phase currents of DOEWIM at low speed, (b) Zoom of the stator phase currents of DOEWIM at low speed

that the harmonics content is less in the case of open-end winding which lead to a better quality of the stator current and less ripples in the electromagnetic torque.

The rotor flux of both structures is shown in Fig. 23. It is obvious that the DOEWIM structure allows us to achieve a significant improvement in harmonics rejection in rotor flux, making it much softer than in the DSIM topology, and this is shown in the obtained zooms of Fig. 23.

\section{Conclusion}

In this paper, the sliding mode control technique combined with the space vector pulse width modulation has been applied to ensure the control of two topologies of

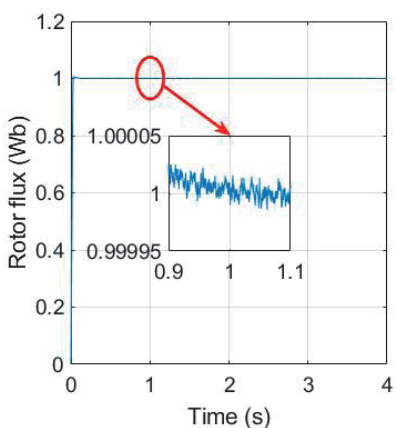

(a)

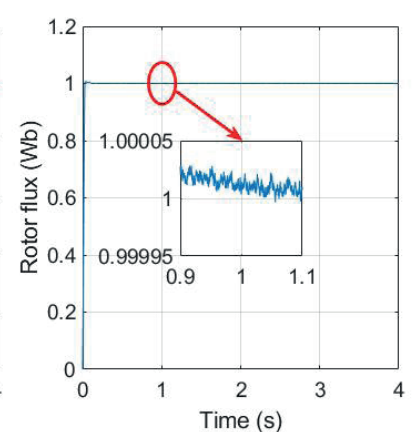

(b)
Fig. 23 The rotor flux at low speed: (a) DSIM, (b) DOEWIM 
dual stator winding induction motor such as the dual star induction motor and the dual open-end winding induction motor. The proposed control of SMC which is applied to both topologies is based on three variables control such as the stator current, the rotor flux and the rotor speed.

The main objective of the present study is to highlight the main advantages of the DOEWIN topology compared to the conventional topology, especially in industrial applications requiring motors with high power where the appearance of the rotor flux ripples, the electromagnetic torque ripples and the increased common mode voltage value can lead to drastically problems over time such as decreased the lifespan of some mechanical parts of the industrial process, especially along the bearings and shafts. On the other

\section{References}

[1] Moati, Y., Kouzi, K. "Investigating the Performances of Direct Torque and Flux Control for Dual Stator Induction Motor with Direct and Indirect Matrix Converter", Periodica Polytechnica Electrical Engineering and Computer Science, 64(1), pp. 97-105, 2020. https://doi.org/10.3311/PPee.14977

[2] Khadar, S., Kouzou, A., Rezzaoui, M. M., Hafaifa, A. "Sensorless Control Technique of Open-End Winding Five Phase Induction Motor under Partial Stator Winding Short-Circuit", Periodica Polytechnica Electrical Engineering and Computer Science, 64(1), pp. 2-19, 2020. https://doi.org/10.3311/PPee.14306

[3] Layadi, N., Djerioui, A., Zeghlache, S., Houari, A., Benkhoris, M. F., Berrabah, F. "A Hybrid Fuzzy Sliding Mode Controller for a Double Star Induction Machine", In: 2018 International Conference on Communications and Electrical Engineering (ICCEE), El Oued, Algeria, 2018, pp. 1-6.

https://doi.org/10.1109/CCEE.2018.8634439

[4] Rahali, H., Zeghlache, S., Benyettou, L., Benalia, L. "Backstepping Sliding Mode Controller Improved with Interval Type-2 Fuzzy Logic Applied to the Dual Star Induction Motor", International Journal of Computational Intelligence and Applications, 18(2), Article number: $1950012,2019$.

https://doi.org/10.1142/S1469026819500123

[5] Layadi, N., Zeghlache, S., Benslimane, T., Berrabah, F. "Comparative Analysis between the Rotor Flux Oriented Control and Backstepping Control of a Double Star Induction Machine (DSIM) under Open-Phase Fault", Advances in Modelling and Analyis C, 72(4), pp. 292-311, 2017.

https://doi.org/10.18280/ama_c.720407

[6] Marouani, K., Baghli, L., Hadiouche, D., Kheloui, A., Rezzoug, A. "A New PWM Strategy Based on a 24-Sector Vector Space Decomposition for a Six-Phase VSI-Fed Dual Stator Induction Motor", IEEE Transactions on Industrial Electronics, 55(5), pp. 1910-1920, 2008.

https://doi.org/10.1109/TIE.2008.918486 side, the use of the DOEWIM topology allow reducing remarkably the harmonics content in the stator currents, which means that better power quality can and improved power factor can be achieved, hence avoiding equipment aging and reducing power consumption costs in industrial plants when the DOEWIN is used with the adequate control technique SMC combined with SVPWM.

It can be concluded that the application of sliding mode control based on FOC and combined with SVPWM on dual open-end winding induction motor offers improved dynamics performance against load torque and rotor speed variation which makes this kind of motor to be a promising solution for high power industrial application requiring more reliability.

[7] Nirsha, K. I., Rajeevan, P. P. "A direct torque control scheme for dual inverter fed induction motor drive with a common de voltage source", In: IECON 2017 - 43rd Annual Conference of the IEEE Industrial Electronics Society, Beijing, China, 2017, pp. 1674-1679. https://doi.org/10.1109/IECON.2017.8216284

[8] Ranjit, M., Gowtami, S., Ganesh Babu, B. "Reduction of Zero Sequence Voltage Using Multilevel Inverter Fed Open-End Winding Induction Motor Drive", Acta Electrotechnica et Informatica, 16(4), pp. 52-60, 2016.

https://doi.org/10.15546/aeei-2016-0032

[9] Vinod, B. R., Shiny, G. "A Multilevel Inverter fed Direct Torque Control Strategy for an Induction Motor using PI Controllers", International Journal of Engineering and Advanced Technology (IJEAT), 7(4), pp. 90-99, 2018.

[10] Reddy, B. V., Somasekhar, V. T. "A Dual Inverter Fed Four Level Open-End Winding Induction Motor Drive with a Nested RectifierInverter", IEEE Transactions on Industrial Informatics, 9(2), pp. 938-946, 2013.

https://doi.org/10.1109/TII.2012.2223224

[11] Ranjit, M., Brahmananda Reddy, T., Suryakalavathi, M. "Performance Improvements in Open End Winding Induction Motor Drive Using Decoupled PWM Techniques", Energy Procedia, 117, pp. 810-817, 2017. https://doi.org/10.1016/j.egypro.2017.05.198

[12] Saad, K., Abdellah, K., Ahmed, H., Iqbal, A. "Investigation on SVM Backstepping sensorless control of five-phase open-end winding induction motor based on model reference adaptive system and parameter estimation", Engineering Science and Technology, an International Journal, 22(4), pp. 1013-1026, 2019. https://doi.org/10.1016/j.jestch.2019.02.008 
[13] Nirsha, K. I., Rajeevan, P. P. "Parameter Sensitivity Analysis of DTC Scheme for Dual Inverter fed Open-end Winding IM Drive with Single DC Source", In: 2017 IEEE International WIE Conference on Electrical and Computer Engineering (WIECON-ECE), Dehradun, India, 2017, pp. 64-69. https://doi.org/10.1109/WIECON-ECE.2017.8468935

[14] Prasad, S. V. S., Singh, R. R., Somasekhar, V. T., Lakhimsetty, S. "Performance evaluation of an induction motor drive with direct torque control for open-end winding and cascaded three-level topologies", In: 2017 6th International Conference on Computer Applications in Electrical Engineering-Recent Advances (CERA), Roorkee, India, 2017, pp. 308-313. https://doi.org/10.1109/CERA.2017.8343346

[15] Kumar, K. V. P., Kumar, T. V. "Improvised direct torque control strategies of open-end winding PMSM fed with multi-level inversion", In 2018 IEEE International Conference on Industrial Technology (ICIT), Lyon, France, 2018, pp. 425-430. https://doi.org/10.1109/ICIT.2018.8352215

[16] Babu, M. V., Rajeevan, P. P. "Current error space vector based PWM scheme for dual inverter fed open-end winding induction motor with single DC-source", In: IECON 2017 - 43rd Annual Conference of the IEEE Industrial Electronics Society, Beijing, China, 2017, pp. 6612-6617. https://doi.org/10.1109/IECON.2017.8217154

[17] Lakhimsetty, S., Prasad, V. K. J. D. "Comparative performance analysis of decoupled SVPWM techniques for a four - level open end winding induction motor drive", In: 2016 IEEE 7th Power India International Conference (PIICON), Bikaner, India, 2016, pp. 1-6. https://doi.org/10.1109/POWERI.2016.8077334

[18] Karampuri, R., Jain, S., Somasekhar, V. T. "Phase displaced SVPWM technique for Five-Phase Open-End Winding Induction Motor drive", In: 2016 IEEE Students' Conference on Electrical, Electronics and Computer Science (SCEECS), Bhopal, India, 2016, pp. 1-6.

https://doi.org/10.1109/SCEECS.2016.7509283

[19] Rahali, H., Zeghlache, S., Benalia, L., Layadi, N. "Sliding Mode Control Based on Backstepping Approach for a Double Star Induction Motor (DSIM)", Advances in Modelling and Analysis C, 73(4), pp. 150-157, 2018.

https://doi.org/10.18280/ama_c.730404

[20] Khouidmi, H., Massoum, A. "Reduced-Order Sliding Mode Observer-based Speed Sensorless Vector Control of Double Stator Induction Motor", Acta Polytechnica Hungarica, 11(6), pp. 229-249, 2014.

https://doi.org/10.12700/APH.11.06.2014.06.14

[21] Lahcen, L., Bouchiba, B. "Fuzzy Sliding Mode Controller for Induction Machine Feed by Three Level Inverter", International Journal of Power Electronics and Drive System (IJPEDS), 9(1), pp. 55-63, 2018. https://doi.org/10.11591/ijpeds.v9.i1.pp55-63

[22] Abderazak, S., Farid, N. "Comparative study between Sliding mode controller and Fuzzy Sliding mode controller in a speed control for doubly fed induction motor", In: 2016 IEEE 4th International Conference on Control Engineering \& Information Technology (CEIT), Hammamet, Tunisia, 2016, pp. 1-6. https://doi.org/10.1109/CEIT.2016.7929044
[23] Layadi, N., Zeghlache, S., Berrabah, F., Bentouhami, L. "Comparative Study between Sliding Mode Control and Backstepping Control for Double Star Induction Machine (DSIM) under Current Sensor Faults", International Journal of Information Technology and Electrical Engineering, 6(6), pp. 67-77, 2017.

[24] Satheesh, G., Bramhananda Reddy, T., Sai Babu, Ch. "Space-vector based PWM switching strategy for a Four-level dual inverter fed open-end Winding induction motor drive", In: IEEE-International Conference on Advances in Engineering, Science and Management (ICAESM -2012), Tamil Nadu, India, 2012, pp. 111-115.

[25] Reddy, B. V., Somasekhar, V. T. "A space-vector modulation scheme for a four-level dual inverter fed open-end winding induction motor drive", In: 2012 IEEE 5th India International Conference on Power Electronics (IICPE), Delhi, India, 2012, pp. 1-6. https://doi.org/10.1109/IICPE.2012.6450397

[26] Satheesh, G., Bramhananda Reddy, T., Sai Babu, CH. "SVPWM Based DTC of OEWIM Drive Fed with Four Level Inverter with Asymmetrical DC Link Voltages", International Journal of Soft Computing and Engineering, 3(1), pp. 64-68, 2013.

[27] Shiny, G., Baiju, M. R. "Space Vector based PWM scheme without sector identification for a 4-level dual inverter fed induction motor drive with asymmetrical DC link voltages", In: 2010 Twenty-Fifth Annual IEEE Applied Power Electronics Conference and Exposition (APEC), Palm Springs, CA, USA, 2010, pp. 1963-1969. https://doi.org/10.1109/APEC.2010.5433503

[28] Fnaiech, M. A., Betin, F., Fnaiech, F., Capolino, G. A. "Sliding Mode Control for Dual Three-phase Induction Motor Drives", In: 2006 IEEE International Symposium on Industrial Electronics, Montreal, Quebec, Canada, 2006, pp. 2281-2285. https://doi.org/10.1109/ISIE.2006.295928

[29] Hazzab, A., Bousserhane, I. K., Kamli, M. "Design of a Fuzzy Sliding Mode Controller by Genetic Algorithms for Induction Machine Speed Control", International Journal of Emerging Electric Power Systems, 1(2), Article number: 1008, 2004. https://doi.org/10.2202/1553-779X.1016

[30] Slotine, J. J. E., Li, W. "Applied Nonlinear Control", Prentice Hall, Hoboken, NJ, USA, 1991.

[31] Hamoudi, F., Chaghi, A. A., Amimeur, H., Merabet, E. K. "Sliding Mode Control with Fixed Switching Frequency for Four-wire Shunt Active Filter", Journal of Electrical Engineering and Technology, 6(5), pp. 647-657, 2011. https://doi.org/10.5370/JEET.2011.6.5.647

[32] Ahmed, M., Karim, F. M., Abdelkader, M., Abdelber, B. "Input output linearization and sliding mode control of a permanent magnet synchronous machine fed by a three levels inverter", Journal of Electrical Engineering (JEEEC), 57(4), pp. 205-210, 2006.

[33] Amimeur, H., Aouzellag, D., Abdessemed, R., Ghedamsi, K. "Sliding mode control of a dual-stator induction generator for wind energy conversion systems", International Journal of Electrical Power \& Energy Systems, 42(1), pp. 60-70, 2012. https://doi.org/10.1016/j.ijepes.2012.03.024

[34] Amimeur, H., Abdessemed, R., Aouzellag, D., Merabet, E., Hamoudi, F. "A Sliding Mode Control associated to the FieldOriented Control of Dual-Stator Induction Motor Drives", In: 3rd International Conference on Electrical Engineering (ICEE'09), Algers, Algeria, 2009, pp. 7-12. 
[35] Amimeur, H., Abdessemed, R., Aouzellag, D., Ghedamsi, K., Hamoudi, F., Chekkal, S. "A Sliding Mode Control for Dual-Stator Induction Motor Drives Fed by Matrix Converters" Journal of Electrical Engineering, 11(2), pp. 136-143, 2011.

\section{Appendix}

Table 2 The parameters of the machine used for the both topologies of DSIM and DOEWIM

\begin{tabular}{lccc}
\hline Parameter & Value & Parameter & Value \\
\hline$L_{m}:$ Mutual inductance & $0.3672 \mathrm{H}$ & $K_{f}:$ Friction coefficient & $0.001 \mathrm{~N} \mathrm{~m}(\mathrm{rad} / \mathrm{s})^{-1}$ \\
$L_{r}:$ Rotor inductance & $0.006 \mathrm{H}$ & $P:$ Number of pole pairs & 1 \\
$L_{s 1}=L_{s 2}:$ Stator inductances & $0.022 \mathrm{H}$ & $J:$ Moment of inertia & $0.0625 \mathrm{Kg} \mathrm{m}{ }^{2}$ \\
$R_{s 1}=R_{s 2}:$ Stator resistances & $3.72 \mathrm{H}$ & $V_{n}:$ Nominal voltage & $220 \mathrm{~V}$ \\
$R_{r}:$ Rotor resistance & $2.12 \mathrm{H}$ & $P_{n}:$ Nominal power & $4.5 \mathrm{KW}$ \\
\hline
\end{tabular}

